\title{
Involvement of the metabolic sensor GPR81 in cardiovascular control
}

\author{
Kristina Wallenius, ${ }^{1}$ Pia Thalén, Jan-Arne Björkman, ${ }^{1}$ Petra Johannesson, ${ }^{1}$ John Wiseman, ${ }^{2}$ \\ Gerhard Böttcher, ${ }^{3}$ Ola Fjellström, ${ }^{1}$ and Nicholas D. Oakes ${ }^{1}$
}

${ }^{1}$ CVMD iMed, ${ }^{2}$ Discovery Sciences, and ${ }^{3}$ Drug Safety \& Metabolism, AstraZeneca R\&D Gothenburg, Sweden.

\begin{abstract}
GPR81 is a receptor for the metabolic intermediate lactate with an established role in regulating adipocyte lipolysis. Potentially novel GPR81 agonists were identified that suppressed fasting plasma free fatty acid levels in rodents and in addition improved insulin sensitivity in mouse models of insulin resistance and diabetes. Unexpectedly, the agonists simultaneously induced hypertension in rodents, including wild-type, but not GPR81-deficient mice. Detailed cardiovascular studies in anesthetized dogs showed that the pressor effect was associated with heterogenous effects on vascular resistance among the measured tissues: increasing in the kidney while remaining unchanged in hindlimb and heart. Studies in rats revealed that the pressor effect could be blocked, and the renal resistance effect at least partially blocked, with pharmacological antagonism of endothelin receptors. In situ hybridization localized GPR81 to the microcirculation, notably afferent arterioles of the kidney. In conclusion, these results provide evidence for a potentially novel role of GPR81 agonism in blood pressure control and regulation of renal vascular resistance including modulation of a known vasoeffector mechanism, the endothelin system. In addition, support is provided for the concept of fatty acid lowering as a means of improving insulin sensitivity.
\end{abstract}

Conflict of interest: All authors are or have been employed by AstraZeneca R\&D Gothenburg.

Submitted: December 28, 2016

Accepted: August 24, 2017

Published: October 5, 2017

Reference information: JCI Insight. 2017;2(19):e92564. https://doi.org/10.1172/jci. insight.92564.

\section{Introduction}

GPR81 belongs to a family of hydroxy-carboxylic acid (HCA) receptors including the GPR109a receptor (1). The endogenous ligand for GPR81 is lactate (2), a metabolite produced when glycolysis exceeds the capacity to oxidize pyruvate. Lactate acts as an agonist at millimolar concentrations (3), which are achieved systemically under physiologically challenging (4) and pathophysiological circumstances (5) but also locally under unstressed conditions in specific tissues (6-10). Agonism of GPR81 in adipocytes results in inhibition of lipolysis via the Gi mechanism involving lowering cAMP and downstream dephosphorylation of hormone-sensitive lipase leading to reduced hydrolysis of triglycerides to glycerol and fatty acids (11). GPR81's role in regulating lipolysis along with its predominant adipose tissue expression prompted our initial interest in GPR81, as limiting lipid supply to nonadipose tissue could be a means of reversing insulin resistance associated with type 2 diabetes (12-14). While some basic data for novel GPR81 agonists exist in the literature $(15,16)$, there are, to our knowledge, no reported repeated-dosing effects in disease models.

Beyond the control of adipocyte lipolysis, the current understanding of the roles of GPR81 is limited. GPR81 is expressed at much lower levels in the brain, where it seems to be involved in neuronal signalling, as well as the retina where it has been implicated in regulation of blood flow to meet metabolic demands (17-20). It is also induced in several cancer types where it appears to play a role in the adaptation to the ischemic tumor microenvironment (21).

In the present study, GPR81 agonists were discovered with the initial aim to test the hypothesis that GPR81 agonism, via antilipolysis, would improve insulin sensitivity and glucose control in disease models of the metabolic syndrome. Indeed, repeated-dosing studies confirmed this hypothesis. In addition, however, an integrative pharmacologic discovery approach revealed an unexpected although consistent and robust hypertensive effect. This led us to investigate the role of GPR81 in cardiovascular control. We tested GPR81 dependence using GPR81-deficient mice and performed detailed cardiovascular studies in anesthetized dogs and rats. The results suggest a potentially novel role for GPR81 in renal vascular control. 
<smiles>CCOc1cc(Cl)c(C(=O)NC(=O)Nc2nc3ccc(S(=O)(=O)C4CCN(C)CC4)cc3s2)cc1-n1cccn1</smiles><smiles>CCOc1cc(Cl)c(C(=O)NC(=O)Nc2nc3ccc(CN4CCN(C)CC4)cc3s2)cc1N1CCOCC1</smiles>

Figure 1. Structures of GPR81 agonists, AZ1 and AZ2, as well as the reference compound 3-chloro-5-hydroxybenzoic acid (CHBA). AZ1 (A) and AZ2 (B) were identified using high-throughput screening of the AstraZeneca proprietary compound collection. CHBA (C) has been previously established as a GPR81 agonist (15).

\section{Results}

Identification of 2 potentially novel GPR81 agonists: AZ1 and AZ2. Figure 1 shows the structures of 2 GPR81 agonists, AZ1 (Figure 1A) and AZ2 (Figure 1B), with properties suitable to test the concept that GPR81 agonism could reverse impairments in glucose control in rodent models of the metabolic syndrome. Figure $1 \mathrm{C}$ shows the structure of the reference compound 3-chloro-5hydroxybenzoic acid (CHBA) (15). The selection of AZ1 and AZ2 was the result of a series of discovery steps, summarized in Table 1. Briefly, these were (a) high-throughput screening of the AstraZeneca proprietary compound collection based on suppression of forskolin-stimulated cAMP in cells transfected with GPR81, (b) inhibition of glycerol release from forskolin-stimulated primary rat and human adipocytes (see also Figure 2), (c) pharmacokinetic properties adequate for oral repeated-dosing, and (d) acute inhibition of fasting-induced lipolysis in anesthetized rats (Table 1). Supplemental Figure 1 (supplemental material available online with this article; https://doi.org/10.1172/jci.insight.92564DS1) shows the good correlations between the potency estimates from the different in vitro assay screens including human versus rodent assays and between antilipolysis in vitro versus in vivo free fatty acid (FFA) suppression for all of the active compounds tested in each step including AZ1 and AZ2.

FFA lowering is dependent on GPR81 agonism. The ability of AZ1 and AZ2 to lower FFA in mice in the 6-hour fasting state was studied. Figure 3A shows a dose-dependent decrease in FFA levels in lean mice following oral administration of AZ1. The highest dose of AZ1, $20 \mu \mathrm{mol} / \mathrm{kg}$, was selected for further testing in GPR81$\mathrm{WT}$ and $-\mathrm{KO}$ mice to confirm the dependence of FFA lowering

on GPR81 (Figure 3B). Fasting FFA levels were similar in the GPR81-WT and -KO mice, consistent with the results of Ahmed et al. (3). As expected in GPR81-WT mice, FFA levels were reduced following AZ1 administration. By contrast, FFA levels were not lowered in the GPR81-KO mice (Figure 3B), despite equivalent plasma exposures of $\mathrm{AZ1}$ (WT, $0.37 \pm 0.04 \mu \mathrm{M}$; KO, $0.36 \pm 0.06 \mu \mathrm{M}$ ). This pattern of results was confirmed with AZ2 (Figure 3C, plasma exposure WT, $1.1 \pm 0.1 \mu \mathrm{M} ; \mathrm{KO}, 1.4 \pm 0.1 \mu \mathrm{M}$ ).

We then studied if a single dose of AZ1 could suppress lipolysis in ob/ob mice. The results presented in Figure 3D show that AZ1 significantly reduced plasma FFA levels by 33\% in the ob/ob mice (compared with $74 \%$ in the lean animals, Figure $3 \mathrm{~A}$ ). The tendency for blunted FFA lowering in ob/ob mice was explored by examining the expression of the target receptor in white adipose tissue (Figure 3E). These results confirm previously published data showing reduced GPR81 expression in obese mice $(22,23)$.

Insulin-sensitizing and antidiabetic effects following repeated dosing with GPR81 agonist. Insulin-resistant dietinduced obese (DIO) mice were dosed daily with AZ1 $(20 \mu \mathrm{mol} / \mathrm{kg})$ or vehicle at the start of the night (active period), the time when they would normally eat the main portion of their daily food intake. Following 20 days of treatment, body weight was not significantly different between the groups (vehicle, $47.6 \pm 0.8 \mathrm{~g}$ vs. AZ1, $45.5 \pm 1 \mathrm{~g}$ ). At this time point an oral glucose tolerance test was performed in the 4-hour fasted state (Figure 4). At $t=0$ minutes, before glucose administration, there was no group difference in plasma glucose levels in these nondiabetic animals but a reduction in fasting insulin in the AZ1 versus the vehicle group (Figure 4), translating to a large decrease in the relative homeostatic model assessment of insulin resistance (HOMA-IR) index (calculated from the product of glucose and insulin levels) from vehicle $100 \% \pm 26.2 \%$ versus AZ1 
A

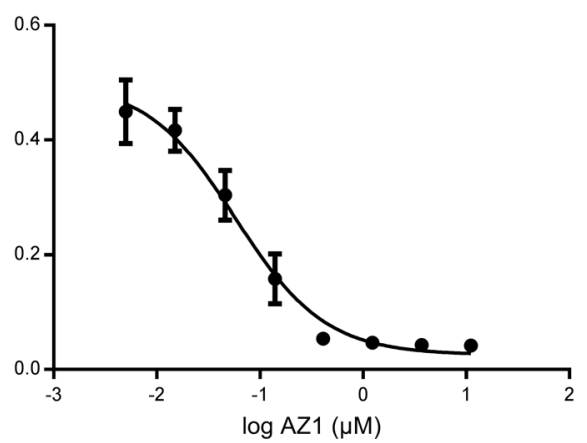

B

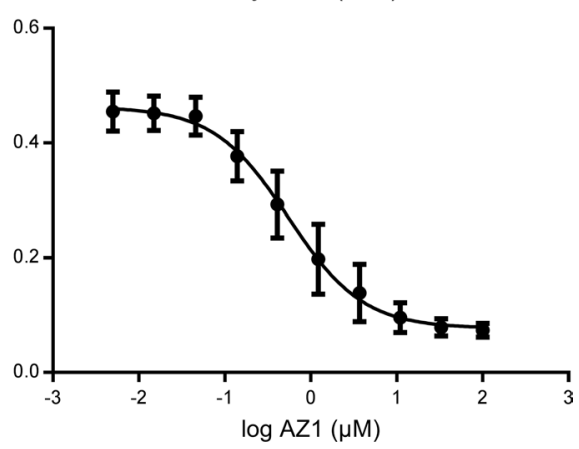

Figure 2. GPR81 agonism inhibits adipocyte lipolysis in vitro. (A) Representative dose-response curve showing the ability of AZ1 to suppress forskolin-stimulated release of glycerol from primary rat adipocytes $\left(E_{50} 58 \mathrm{nM}\right)$ and $(B)$ primary human adipocytes $\left(\mathrm{EC}_{50} 550 \mathrm{nM}\right)$. Results shown as the mean $\pm \mathrm{SEM}, n=5$.

$31.6 \% \pm 6.5 \%(P<0.05)$, suggesting insulin sensitization. In response to the glucose challenge, glucose AUC was similar in both groups (Figure 4, A and C), while the AUC for insulin was markedly reduced in the AZ1 treated group versus vehicle (Figure 4, B and D), again consistent with GPR81-agonist-induced insulin sensitization. Daily treatment was continued for 1 more week until a final fasting blood sample was collected. Supplemental Table 1 shows the effects on body weight, plasma biomarkers, and compound exposure levels at the end of the 28-day study. Body weight gain was significantly reduced in the substance-treated group compared with the vehicle-treated group. Again, HOMA-IR was significantly reduced in the GPR81-agonisttreated group compared with vehicle, suggesting improved insulin sensitivity. Plasma FFA levels were significantly reduced in the GPR81-treated group, suggesting durable effects on FFA lowering.

Next, we tested the effect of 2 weeks of treatment with AZ1 ( $20 \mu \mathrm{mol} / \mathrm{kg} /$ day) in obese diabetic ob/ob mice, with effects summarized in Supplemental Table 2. Body weight gain and fasting plasma glucose were similar in the AZ1- and vehicle-treated groups. Fructosamine levels were reduced by the GPR81 agonist, suggesting improved 24-hour glucose control. Insulin levels and the HOMA-IR were markedly reduced in the AZ1-treated group versus vehicle, consistent with enhanced insulin sensitivity. FFA levels tended to be lower with treatment, although the difference did not achieve statistical significance. We suspect that the failure to achieve statistical significance for this particular case is due to (a) a short fasting period prior to FFA sampling, (b) the high variability in the ob/ob, and (c) relatively low efficacy in this obese model.

Acute hypertensive effects of GPR81 agonists in rats. During screening for acute FFA-lowering effects in barbiturate-anesthetized rats (with few animals per group), an unexpected but consistent finding seen with all GPR81 agonists tested was hypertension. These effects are illustrated for AZ2 and the GPR81 reference agonist CHBA in Figure 5. Figure 5A shows the effect of vehicle ( $5 \%$ mannitol) or AZ2 $(0.9 \mu \mathrm{mol} / \mathrm{kg} / \mathrm{min}$ for 15 minutes, resulting in peak exposures at 15 minutes of $2.6 \pm 0.9$ $\mu \mathrm{M})$ on FFA levels while Figure $5, B$ and $C$ show the effect on percentage change versus baseline in mean arterial pressure (MAP) and heart rate (HR). Similar data sets are shown for

Table 1. Basic properties of the GPR81 agonists, AZ1 and AZ2

\begin{tabular}{|c|c|c|}
\hline & AZ1 & AZ2 \\
\hline $\begin{array}{l}\text { GPR81 cAMP EC } \text { c }_{50}(\mathrm{nM}) \\
\text { Human, rat, mouse }\end{array}$ & $23,10,5.7$ & $74,310,180$ \\
\hline $\begin{array}{l}\text { GPR109a cAMP EC }_{50}(\mathrm{nM}) \\
\text { Human, rat, mouse }\end{array}$ & $120,72,68$ & $2,200,1,200,1,300$ \\
\hline Rat primary adipocytes $\mathrm{EC}_{50}(\mathrm{nM})$ & 58 & 580 \\
\hline Human primary adipocytes $\mathrm{EC}_{50}(\mathrm{nM})$ & 550 & 1,600 \\
\hline Rat CL i.v. $(\mathrm{ml} / \mathrm{min} / \mathrm{kg})$ & 2.5 & $51^{A}$ \\
\hline Rat $\mathrm{t}_{1 / 2}$ i.v. (h) & 2.0 & $3.2^{\mathrm{A}}$ \\
\hline Rat Bioavailability (\%) & 21 & $19^{A}$ \\
\hline Mouse CL i.v. $(\mathrm{ml} / \mathrm{min} / \mathrm{kg})$ & & $41^{\mathrm{B}}$ \\
\hline Mouse $t_{1 / 2}$ i.v. (h) & & $5.0^{\mathrm{B}}$ \\
\hline Mouse Bioavailability (\%) & & 100 \\
\hline Rat in vivo $F F A$ suppression $\mathrm{EC}_{50}(\mathrm{nM})$ & 40 & 160 \\
\hline \multicolumn{3}{|c|}{$\begin{array}{l}n \geq 3 \text { except }{ }^{A} n=2 \text { and }{ }^{B} n=1 \text {. Potency to suppress forskolin-stimulated cyclic } \\
\text { adenosine monophosphate (cAMP) was assessed in Chinese hamster ovary } \\
\text { cells overexpressing human, rat, and mouse GPR81 or GPR109a. Potency to } \\
\text { suppress forskolin-stimulated lipolysis was assessed in primary rat and human } \\
\text { adipocytes. Pharmacokinetic characteristics determined in the rat and mouse } \\
\text { were estimated plasma clearance rate (CL), terminal plasma half time }\left(t_{1 / 2}\right) \text {, } \\
\text { and oral bioavailability. In vivo potency to suppress fasting plasma free fatty } \\
\text { acid (FFA) levels was assessed in anesthetized rats. CAMP, cyclic adenosine } \\
\text { monophosphate; } C L \text {, clearance. }\end{array}$} \\
\hline
\end{tabular}


A

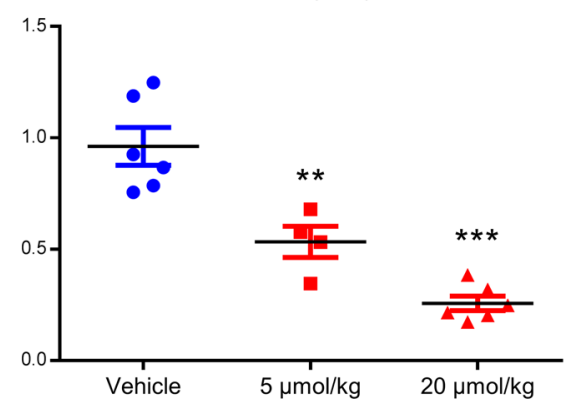

B

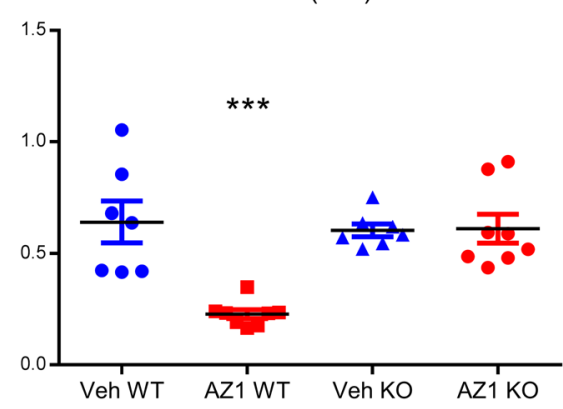

D

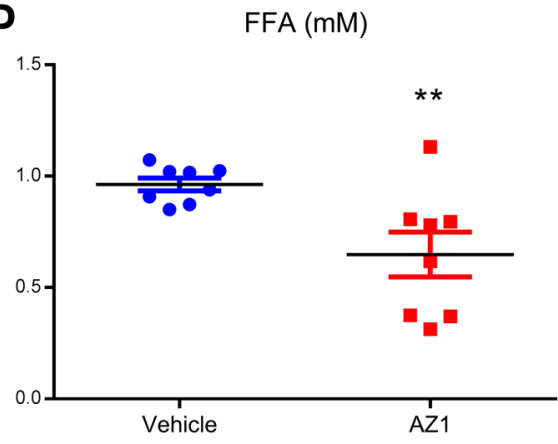

C

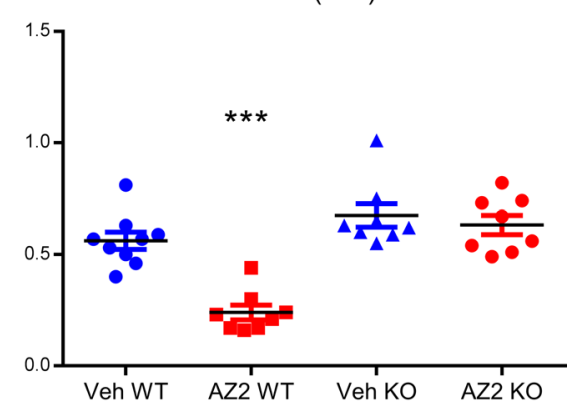

E

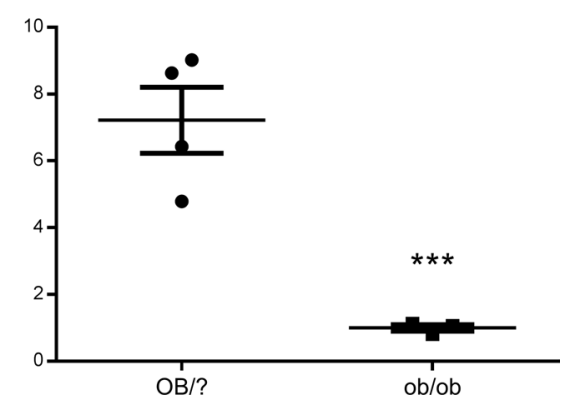

Figure 3. GPR81 agonists suppress fasting plasma free fatty acids (FFAs) in vivo. (A) Dose-dependent suppression of plasma FFAs in lean mice following oral administration of AZ1 (5 and $20 \mu \mathrm{mol} / \mathrm{kg}) .{ }^{* *} P<0.01,{ }^{* *} P<$ 0.001 versus vehicle (Veh) (ANOVA, Bonferroni corrected, $n=4-6)$. Ability of $A Z 1$ (B) and AZ2 (C) to suppress plasma FFA is dependent on GPR81. FFA in wild-type (WT) and GPR81-knockout (KO) mice following single oral administration of vehicle (Veh), AZ1 (20 $\mu \mathrm{mol} / \mathrm{kg})$, or AZ2 $(50 \mu \mathrm{mol} / \mathrm{kg}) .{ }^{* *} P<0.001$, versus Veh WT (ANOVA, Bonferroni corrected). $n=7-8$ (B) and 8-9 (C). (D) FFA in ob/ob mice is decreased by AZ1 $(20 \mu \mathrm{mol} / \mathrm{kg}) .{ }^{*} P<0.01$, versus Veh WT (Student's $t$ test, $n=8$ ). (E) Downregulation of expression of GPR81 gene in epididymal adipose tissue from obese ob/ob mice versus lean $\mathrm{OB} /$ ? mice. ${ }^{* *} P<0.001$, versus Veh WT (Student's $t$ test, $n=3-4$ ). Results shown as individual data points together with the mean \pm SEM.

CHBA $(10 \mu \mathrm{mol} / \mathrm{kg} / \mathrm{min}$ ) and its vehicle (saline) (Figure 5, D-F). Since we studied the effects of the agonists at submaximal doses needed for FFA suppression $\left(\sim 4 \times \mathrm{ED}_{50}\right)$, these data suggest that there is no separation of the hypertensive from the FFA-lowering effects. In the anesthetized state, treatment-induced bradycardia was also consistently observed (Figure 5, C and F), a phenomenon not seen in conscious rats (data not shown).

AZ2-induced hypertension is dependent on the GPR81 receptor. GPR81-KO mice were employed to test the dependence of the agonist-induced hypertensive effect on GPR81. MAP and HR were continuously monitored during a 2-day baseline period and a 4-day treatment period. The diurnal profiles for WT versus GPR81-KO mice averaged over baseline are shown in Supplemental Figure 2. The profiles show typical circadian patterns in both groups. Deficiency of GPR81 had no obvious effect on cardiovascular phenotype, with no differences in average 24-hour MAP or HR in the 2 groups of mice during baseline. Figure 6A shows the MAP responses in WT and $\mathrm{KO}$ mice to vehicle or AZ2 $(50 \mu \mathrm{mol} / \mathrm{kg})$. In response to the oral administration procedure at $\mathrm{t}=0, \mathrm{MAP}$ increased in all groups. Within approximately 1 hour, MAP then returned to baseline in all except the AZ2-treated WT group where MAP remained increased for several hours (Figure 6A). Averaged over 24 hours, AZ2 increased MAP by approximately $5 \mathrm{mmHg}$ in WT but not $\mathrm{KO}$ mice (Figure $6 \mathrm{~B}$ ). There was no difference in average MAP responses to vehicle between WT and KO mice. The HR responses were not significantly affected by AZ2 or genotype (Figure 6, C and D).

Involvement of endothelin and adrenergic systems in the AZ2-induced pressor effect in the rat. Pilot experiments were performed in the anesthetized rat to broadly test the involvement of established regulators of vascular tone, including the use of pharmacological blocking agents. The results hinted at the potential involvement of 2 powerful regulators of vascular resistance, the endothelin (ET) and adrenergic systems. 
A
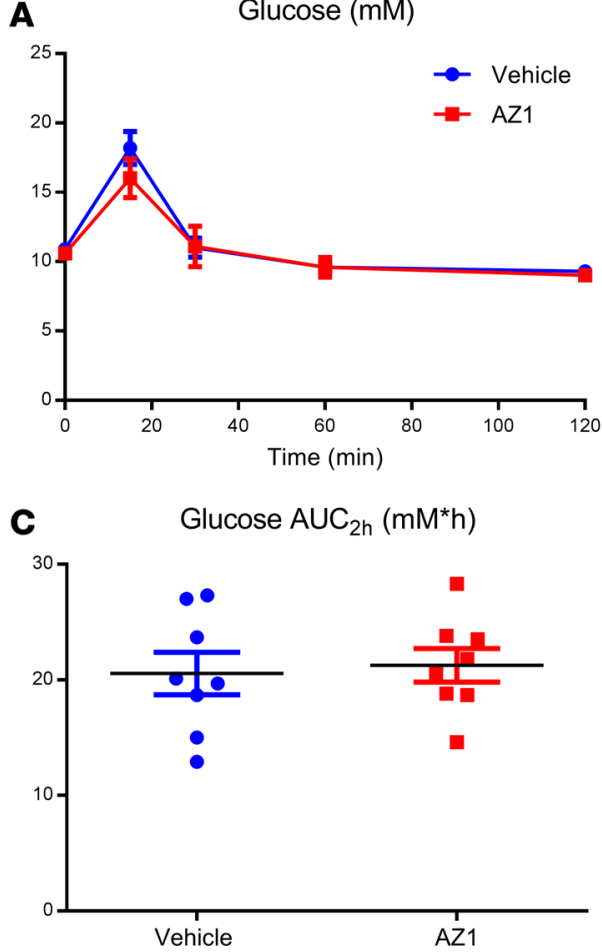

B

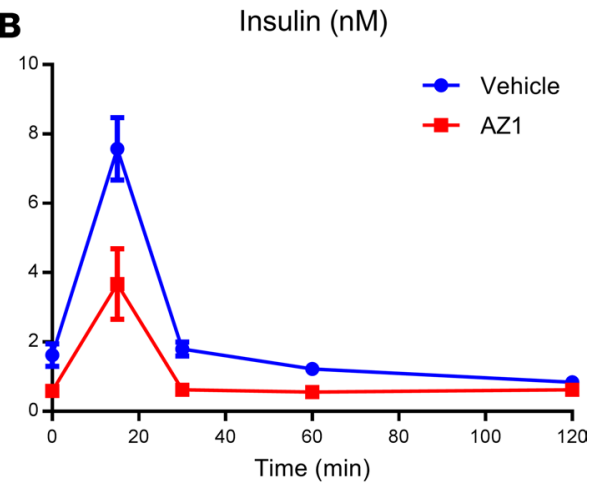

D

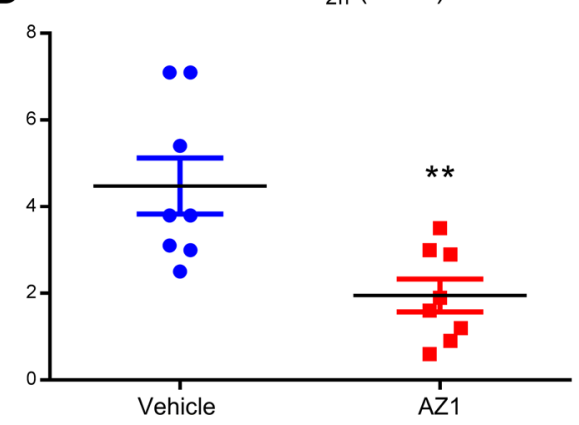

Figure 4. The GPR81 agonist, AZ1, improves insulin sensitivity in dietinduced obese (DIO) mice. Male mice, fed a high-fat (60\% calories) diet for 15 weeks, were daily dosed for 3 weeks by oral gavage, with either vehicle or AZ1 $(20 \mu \mathrm{mol} / \mathrm{kg})$, at the beginning of the dark cycle. Responses to an oral glucose challenge $(1 \mathrm{~g} / \mathrm{kg})$, given in the 4 -hour fasted state at $t=0$, are shown for plasma glucose (A) and for plasma insulin (B). Corresponding areas under the curves (AUC), between 0 and 120 minutes, for (C) plasma glucose $(\mathrm{mM} \times \mathrm{h})$ and $(\mathbf{D})$ insulin $(n M \times h)$. Results shown as the mean \pm SEM ( $\mathbf{A}$ and $\mathbf{B}$ ) or individual data points together with the mean \pm SEM (C and D). ${ }^{* *} P<0.01$ versus vehicle (Student's $t$ test, $n=8$ (group).

These observations were followed up by more thoroughly studying the cardiovascular responses to AZ2 on top of the nonselective ET receptor antagonist, bosentan, or the nonselective $\alpha$-adrenoceptor $(\alpha$-AR) antagonist, phentolamine.

Bosentan (given prior to $A Z 2$ ) did not significantly impact $M A P, H R$, or a crude index of total peripheral resistance $(T P R i=M A P / H R)$ compared with vehicle controls (Supplemental Table 3), consistent with the original detailed pharmacological profiling work on bosentan in the rat (24). This is presumably the result of a low net level of ET-mediated vasoconstriction in these animals. Except for an initial short-lived tendency for MAP to rise in conjunction with AZ2 infusion start, pretreatment with bosentan effectively blocked the full development of the AZ2-induced pressor effect ( $P$ $<0.05$ versus AZ2 alone, Figure 7, A and B) and increase in TPRi $(P<0.05$ versus AZ2 alone, Figure 7, $\mathrm{E}$ and F). By contrast, the bradycardic response to AZ2 was left intact (Figure 7, C and D). From about 5 minutes into the AZ2 infusion, MAP in the bosentan-pretreated group actually tended to fall below its baseline level (Figure 7A), perhaps a consequence of falling cardiac output (CO) resulting from the persistent bradycardia (Figure 7C). The dissociation of the bradycardia (from the pressor effect) argues against the interpretation that this represented a secondary baroreflex mechanism, indicating that the vascular resistance and bradycardic actions of AZ2 are independent. In contrast to bosentan, phentolamine markedly perturbed the baseline cardiovascular state: lowering MAP (Supplemental Table 3) and TPRi, revealing the importance of adrenergic tone to maintenance of normal blood pressure in these animals. Under these conditions of severe hypotension, phentolamine also prevented the full development of the AZ2-induced pressor effect (Figure 7, A and B) and the increase in TPRi (Figure 7, E and F). Overall, the blocker experiments point to a role for ET receptor agonism and possibly $\alpha$-AR agonism in the AZ2-induced vasoconstrictor/hypertensive effect.

GPR81-agonist-induced hypertension is associated with a marked increase in renal vascular resistance. To further elucidate effects on cardiovascular control, detailed hemodynamic studies were performed in dogs. Baseline characteristics are summarized in Supplemental Table 4. The infusion protocol is depicted in Supplemental Figure 3, and Supplemental Table 5 summarizes the plasma AZ2 concentrations at the end of each dosing interval. Consistent with the results in rodents, AZ2 also acutely induced an increase in MAP in dogs (treatment $\times$ time interaction, $P<0.0001$, Figure 8A) with no effect on HR (Figure 8B). The effect of AZ2 on hypertension was exposure dependent, achieving statistical significance versus vehicle at the 2 highest doses and was reversible, as shown by the tendency towards normalization in association with declining substance levels during the washout phase. The cause of the increased MAP could not be directly attributed to either 
A

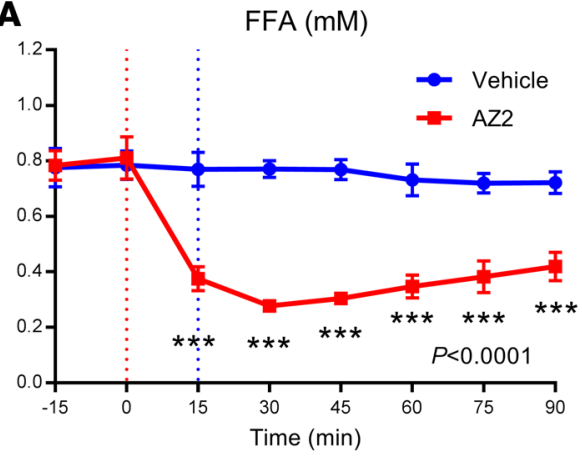

B

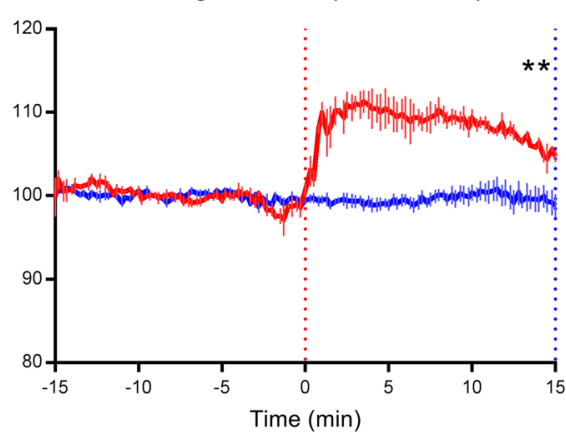

C

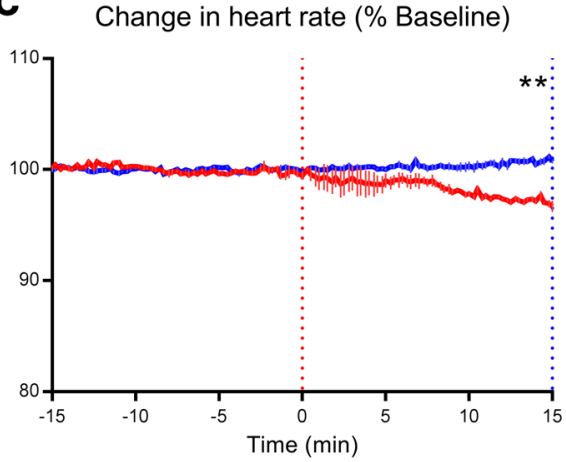

D

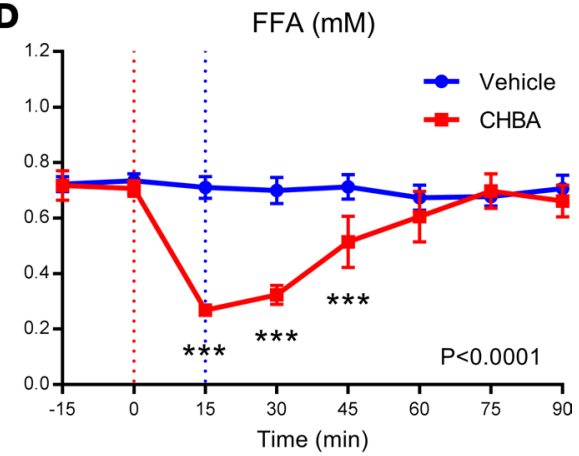

E

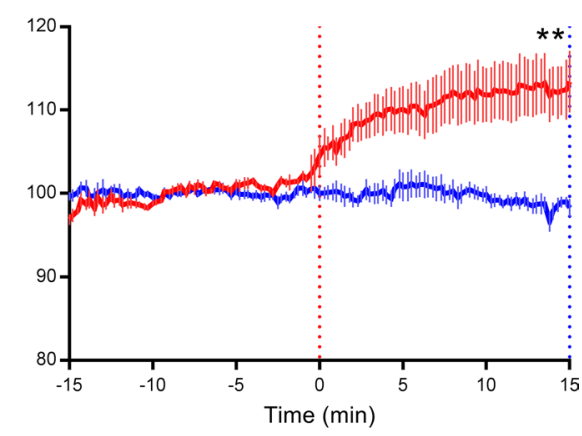

$\mathbf{F}$

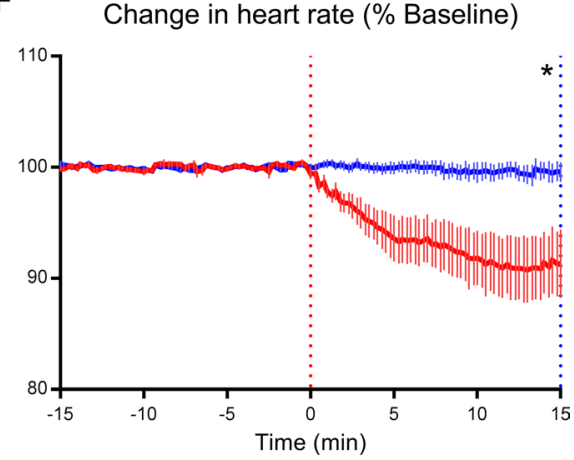

Figure 5. Structurally diverse GPR81 agonists increase blood pressure at doses needed for plasma free fatty acid (FFA) suppression. Adult male Wistar rats were anesthetized in the fasting state and implanted with jugular and carotid catheters and left to stabilize for 2 hours. Following a 15-minute baseline period ( $\mathrm{t}=-15$ to 0 minutes), AZ2 or 3 -chloro5-hydroxybenzoic acid (CHBA) were infused i.v. at $0.9 \mu \mathrm{mol} / \mathrm{kg} / \mathrm{min}$ or $10 \mu \mathrm{mol} / \mathrm{kg} / \mathrm{min}$, respectively, for 15 minutes starting at $t=0$. Panels to the left show results for AZ2. Right panels show CHBA results. (A and $\mathbf{D}$ ) Plasma FFA (mM), ( $\boldsymbol{B}$ and $\mathbf{E})$ mean arterial pressure (MAP) (percentage baseline period mean), and (C and $\mathbf{F}$ ) heart rate (HR) (percentage baseline period mean). Results are the mean \pm SEM. (A) $P$ is treatment $\times$ time interaction (repeated-measures ANOVA). ${ }^{* * *} P<0.001$ $A Z 2$ versus vehicle (Veh) at the corresponding time period (Bonferroni corrected, Veh $n=4, A Z 2 n=3)$. (B) **P $<0.01$ AZ2 versus Veh average MAP (0-15 minutes) (Student's $t$ test, Veh $n=4, A Z 2 n=3$ ). (C) ${ }^{*} P<0.01$ AZ2 versus Veh average HR (0-15 minutes) (Student's $t$ test, Veh $n=4, A Z 2 n=3)$. (D) $P$ is treatment $\times$ time interaction (repeatedmeasures ANOVA). ${ }^{* *} P<0.001$ CHBA versus Veh at the corresponding time period (Bonferroni corrected, Veh $n=5$, CHBA $n=3)$. (E) ${ }^{* *} P$ $<0.01 \mathrm{AZ2}$ versus Veh average MAP $(0-15$ minutes) (Student's $t$ test, Veh $n=5$, CHBA $n$ = 3). (F) ${ }^{*} P<0.01 \mathrm{AZZ}$ versus Veh average HR (0-15 minutes) (Student's $t$ test, Veh $n=5$, CHBA $n=3$ ).

increased CO (Figure 8C) or increased total peripheral resistance (TPR, Figure 8D). Despite tendencies for both of these variables to increase on average in response to AZ2, these trends did not reach statistical significance (treatment $\times$ time interaction, $P<0.05$ ). However, a more detailed regression analysis of the relationship between the increment in MAP $(\triangle \mathrm{MAP})$ and the changes in TPR $(\triangle \mathrm{TPR})$ and $\mathrm{CO}(\triangle \mathrm{CO})$, based on the relationship $\triangle \mathrm{MAP}=\Delta \mathrm{TPR} \times \mathrm{CO}_{\text {Baseline }}+\Delta \mathrm{CO} \times \mathrm{TPR}_{\text {Baseline }}+\Delta \mathrm{CO} \times \Delta \mathrm{TPR}$, indicated that increased TPR was the most important factor in the AZ2-induced hypertension. Thus, $\triangle \mathrm{TPR} \times \mathrm{CO}_{\text {Baseline }}$ could explain $57 \%$ of the variation, while $\triangle \mathrm{CO} \times \mathrm{TPR}_{\text {Baseline }}$ could only explain $7 \%$ of the variation in $\triangle \mathrm{MAP}$ (data not shown). Central venous pressure (CVP) was also assessed in this study and AZ2 induced a slight but highly significant elevation in this variable (treatment $\times$ time interaction, $P<0.0001$, Supplemental Figure 3B).

Blood flow and resistance changes in the renal and femoral beds are summarized in Figure 9 . AZ2 dose-dependently reduced renal blood flow (Figure 9A), a consequence of the rapid resistance increases seen in the renal circulation (Figure 9B). The rapidity of the renal vascular resistance effect was also shown by the transient decreases in resistance (and increase in flow) that could be seen in each experiment at the end of each AZ2 dosing interval, corresponding to the timing of infusion syringe changes, which took approximately 30 seconds to complete. In contrast to the response in the renal bed, the femoral vascular bed in the AZ2 group exhibited an elevated blood flow compared with vehicle (Figure 9C), which occurred in association with no change in vascular resistance (Figure 9D). This implies that the increased hind leg perfusion was a passive consequence of the increase in blood pressure. A pattern similar to that observed for the hindlimb was observed in the coronary circulation (Supplemental Figure 3, C and D). 
A

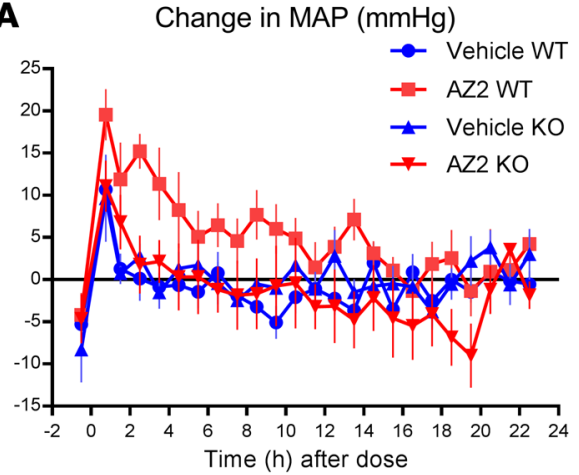

C

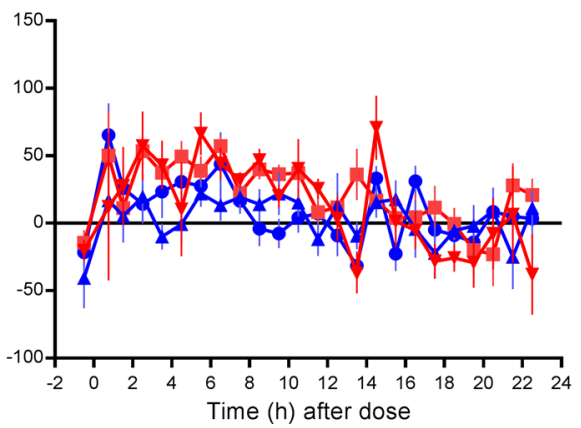

B

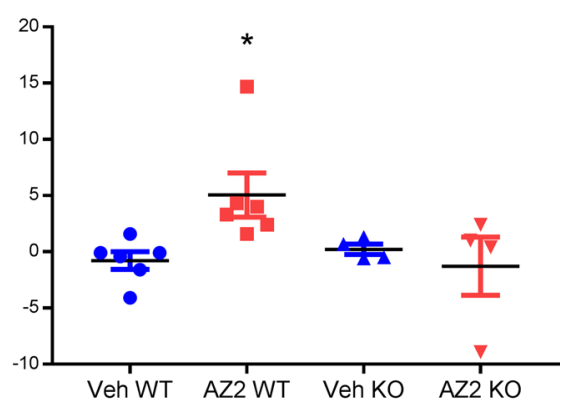

D Change in mean daily HR (bpm)

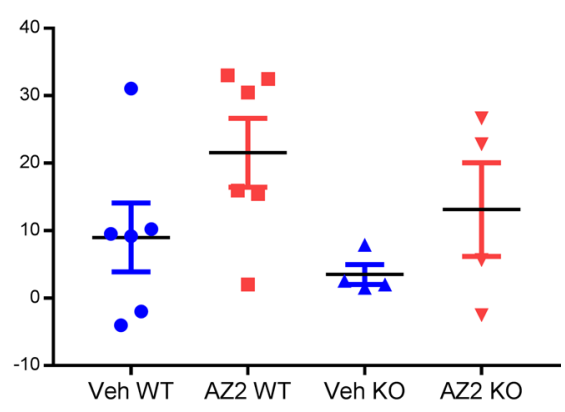

Figure 6. The AZ2-induced hypertension is dependent on GPR81. Adult wild-type (WT) or GPR81-deficient (KO) mice were implanted with carotid catheter/radiotelemetry devices and allowed 2 or more weeks to fully recover their preoperative body weights. Mean arterial pressure (MAP) and heart rate (HR) were then monitored around the clock in conscious unrestrained animals. Following baseline measurements over 2 days (Supplemental Figure 2) animals were orally dosed once daily for 4 days with either AZ2 $(50 \mu \mathrm{mol} /$ $\mathrm{kg}$ ) or vehicle (Veh). Dosing was performed at the same time, $10: 00$, each day corresponding to time $=0$ hours. (A) Change in the 24-hour profile for MAP, between dosing and baseline periods. In conjunction with dosing, AZ2 induces a prolonged increase in MAP in the WT but not the KO mice. (B) Change in MAP, averaged over the whole day, between dosing and baseline periods. AZZ induced hypertension in WT but not the KO mice. ${ }^{*} P<0.05$ versus Veh WT (ANOVA, Bonferroni's multiple comparison test, $n=4-6)$. (C) Change in 24-hour profile for HR. (D) Change in daily mean HR. AZ2 did not significantly affect average HR in either WT or KO mice. Results are the mean \pm SEM.

To assess the direct contribution of the measured change in renal artery resistance (RAR) to $\triangle T P R$, a quantitative analysis was performed. From measured MAP, renal artery flow (RAF), and CO, blood flow and resistance values for the remaining, nonrenal tissues of the body (NKF and NKR, respectively) could be readily calculated, i.e., $\mathrm{NKF}=\mathrm{CO}-2 \times \mathrm{RAF}$ (assuming that the 2 kidneys are identical) and $\mathrm{NKR}=\mathrm{MAP} / \mathrm{NKF}$. From these, the contribution of change in RAR from baseline during AZ2 exposure ( $\triangle \mathrm{RAR})$ to $\triangle \mathrm{TPR}$ can be explicitly estimated by the following: $\triangle \mathrm{TPR}=\left(\mathrm{RAR}_{\mathrm{B}}+\Delta \mathrm{RAR}\right) \times \mathrm{NKR}_{\mathrm{B}} /\left(\mathrm{RAR}_{\mathrm{B}}\right.$ $\left.+\triangle R A R+N K R_{B}\right)-T P R_{B}$, where the subscript $B$ refers to the baseline value of the parameter. From this we calculate that $20 \%-30 \%$ of the observed TPR increases during AZ2 infusion can be directly attributed to the kidneys. Our measurements of regional blood flow, where kidney was the only tissue responding with vasoconstriction, account for only about $20 \%$ of CO and therefore we conclude that other tissues that we have not studied and that are supplied with a major fraction of CO (e.g., gut, skin, and liver) probably also respond with vasoconstriction to GPR81 agonism.

GPR81-agonist effects on renal resistance were also studied in anesthetized rats, with baseline cardiovascular parameters summarized in Supplemental Table 6. A rapid increase in renal vascular resistance in response to AZ2 was also confirmed (Figure 10, A and B). As in the dog, the fact that the renal vasoconstriction occurs together with a reduction in renal blood flow (Figure 10, C and D) demonstrates that this does not represent classic autoregulation. Based on the previous finding that bosentan was apparently able to abolish the systemic vasoconstrictor effect of AZ2, we tested the ability of the ET receptor antagonist to specifically prevent the AZ2-induced vasoconstriction in the kidney. Pretreatment with bosentan once again inhibited the AZ2-induced increase in TPRi (vehicle, $-0.009 \pm 0.006$ [ $\mathrm{n}$ = 6]; AZ2, $0.0294 \pm 0.006[\mathrm{n}=7]$; and bosentan + AZ2, $-0.016 \pm 0.019[\mathrm{n}=4] \mathrm{mmHg} / \mathrm{bpm}$ vs. baseline; AZ2 vs. vehicle, $\mathrm{P}<0.05$; bosentan $+\mathrm{AZ2}$ versus AZ2, $\mathrm{P}<0.05)$. Indeed, bosentan pretreatment also slightly delayed (by approximately 30 seconds) and partially blocked the renal vascular resistance effect of AZ2 (Figure 10, A and B). Clearly though, a substantial fraction of the resistance increase was not blocked by this dose regimen of bosentan. We also attempted to assess whether phentolamine could prevent the renal vascular resistance effect of AZ2. However, in a pilot study, we found that in association with the hypotension, there was a profoundly reduced renal perfusion in response to phentolamine (Supplemental Figure 4), making it very difficult to detect or interpret any AZ2-induced changes in this parameter. This approach was therefore abandoned. 
A

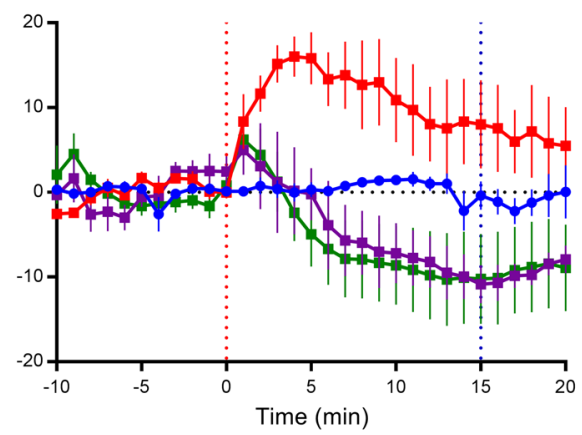

C

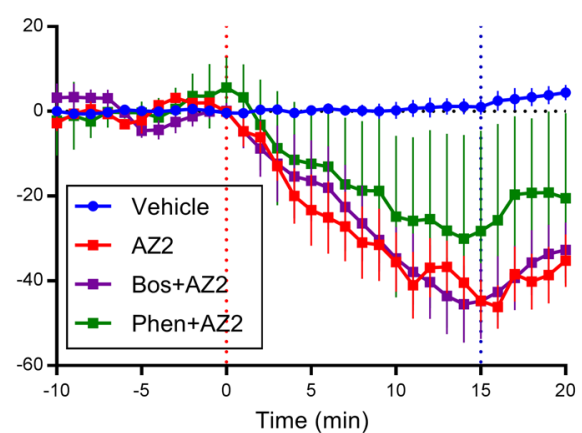

E

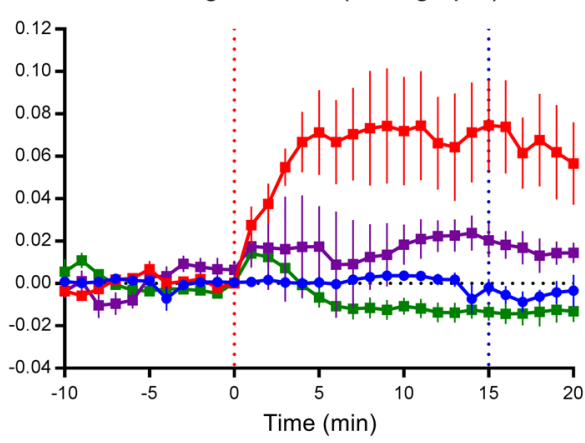

B

Mean change in MAP $(\mathrm{mmHg})$

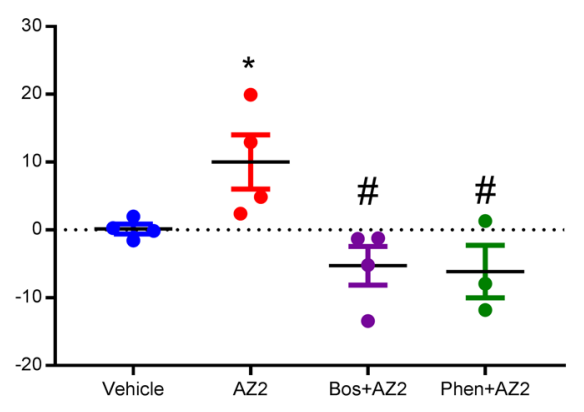

D

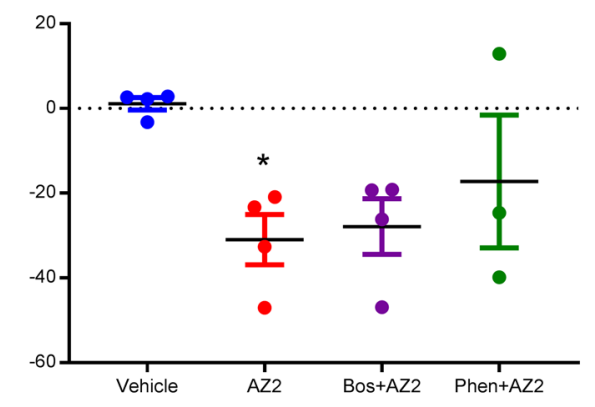

$\mathbf{F}$

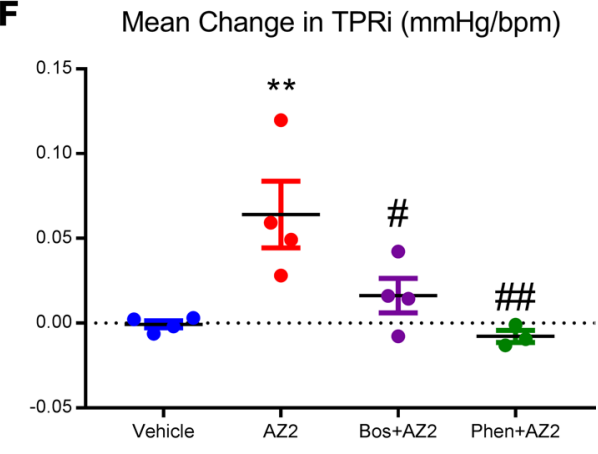

Figure 7. The pressor effect of the GPR81 agonist, AZ2, is substantially prevented by antagonism of either $\alpha$-adrenoceptors ( $\alpha$-ARs) or endothelin (ET) receptors. Adult male Wistar rats were anesthetized and implanted with jugular and carotid catheters, then left to stabilize for 2 hours. Following a 10-minute baseline period $(\mathrm{t}=$ -10 to 0 minutes), AZ2 was given alone (red symbols), or on top of pretreatments (given before -10 minutes): either the dual ET-A/B receptor antagonist, bosentan, $15 \mathrm{mg} / \mathrm{kg}$ i.v. (purple symbols); or the nonselective $\alpha$-AR antagonist, phentolamine, $10 \mathrm{mg} /$ $\mathrm{kg}$ i.v. (green symbols). Changes in mean arterial pressure (MAP), heart rate (HR), and total peripheral resistance index (TPRi) are expressed relative to the average of the baseline period. (A) Minute-by-minute change in MAP. (B) Mean change in MAP averaged over 0-20 minutes. (C) Minuteby-minute change in HR. (D) Mean change in $\mathrm{HR}$ averaged over $0-20$ minutes. (E) Minute-by-minute change in TPRi. (F) Mean change in TPRi averaged over 0-20 minutes. Results are the mean \pm SEM ( $n$ $=3-4$ /group). ${ }^{*} P<0.05,{ }^{* *} P<0.01$ versus vehicle; ${ }^{*} P<0.05,{ }^{\#} P<0.01$ versus $A Z 2$. ANOVA, followed up by multiple comparison test with Holm-Sidak correction.

To obtain clues about the site of renal vasoconstriction, as well as a potential link between the renal and systemic effects, plasma renin responses were assessed following a 15-minute infusion of AZ2. Despite the marked renal vasoconstriction, there was no apparent change in renin level (Figure 10E). To confirm that renin release was responsive in this preparation, we also examined the reaction to modest bloodletting after the main experiments were complete. Bloodletting in the vehicle-treated rats induced a clear elevation in renin levels within 15 minutes of an approximately 4\% blood volume reduction (data not shown).

GPR81 mRNA distribution in mouse and dog kidney. In our hands, immunohistochemistry using commercially available antibodies failed due to lack of specificity. Therefore, we explored expression of the receptor by in situ hybridization (ISH). Figure 11, A and B show the results in GPR81-WT and -KO mice, respectively. In the WT mice, moderate staining was observed corresponding to the afferent arteriole adjacent to the vascular pole of the glomerulus, close to the macula densa of the distal tubulus. Moderate staining was also observed corresponding to the basal part of the glomerular tuft; however, preservation of morphological detail did not allow identification of the exact cell type. In addition, staining was observed in some intertubular cells, possibly blood vessels, and in single cells in the tubular epithelium in the renal cortex. The specificity of the GPR81 mRNA probe was evidenced by a complete lack of staining of all these components in the GPR81-KO mouse kidney (Figure 11B). A tissue distribution similar to that seen for the WT mice was confirmed in dogs (Figure 11C), and this staining pattern was not present in the dog ISH negative control sections (GPR81 mRNA probe exchanged for a scrambled negative control probe; Figure 11D). 
A

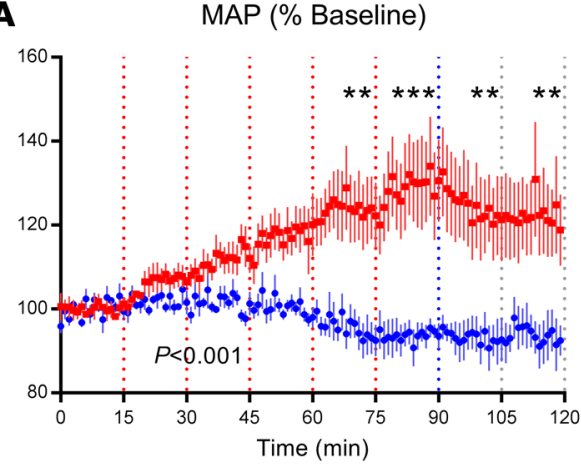

C

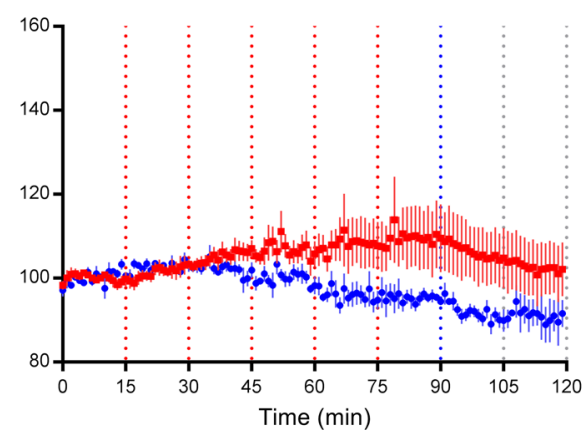

B

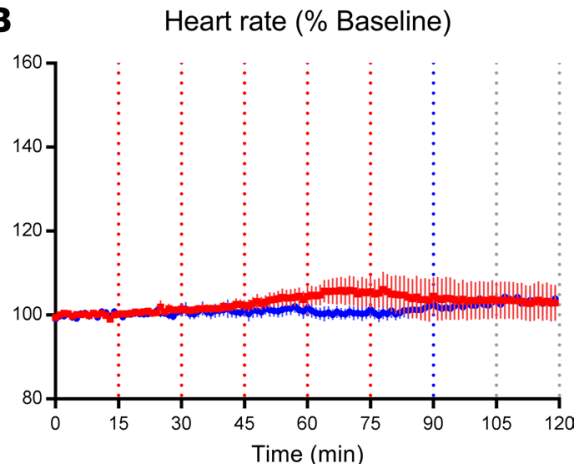

D

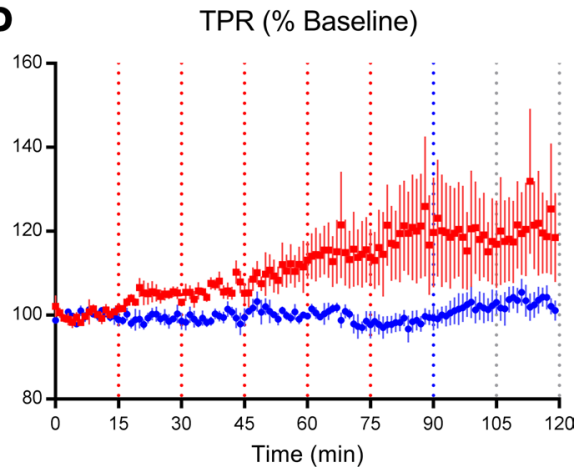

Figure 8. The GPR81 agonist, AZ2, exposuredependently increases blood pressure in anesthetized, ventilated dogs. Immediately after a 15-minute baseline control period (0-15 minutes), AZ2 was administered i.v. in 5 consecutive escalating doses ( 5.5 to 550 $\mathrm{nmol} / \mathrm{kg} / \mathrm{min}$, see Supplemental Figure 3A for diagram), commencing at 15 minutes and ending at 90 minutes, with the start of each dose change indicated by the broken red vertical lines. This was followed by a 30-minute washout period starting at the broken blue vertical line. Responses in AZ2-treated (red) or vehicle-treated (blue) dogs with data expressed as a percentage of their mean values during the baseline period. (A) Mean arterial pressure (MAP). $P$ is treatment $\times$ time interaction significance (repeated-measures ANOVA). ${ }^{*} P<0.01,{ }^{* * *} P<0.001 \mathrm{AZ2}$ versus vehicle at the corresponding time period (Bonferroni corrected, $n=4$ ). (B) Heart rate. (C) Cardiac output. (D) Total peripheral resistance (TPR). Results are the mean \pm SEM.

\section{Discussion}

The most important finding of this study is the discovery that GPR81 has a role in cardiovascular control. This was an unexpected outcome of our exploration of the potential pharmacological utility of GPR81 agonism to improve insulin sensitivity via regulation of adipocyte lipolysis. The current work began by successfully identifying potentially novel GPR81 agonists that were of sufficient potency and selectivity (versus GPR109) to test in vivo. In accord with the known biology, these compounds suppress FFA levels in vivo but they also induce hypertension. We suspected that this was an on-target mechanism given that diverse chemical compounds consistently increased blood pressure. Definitive evidence is provided by the absence of the hypertensive effect in GPR81-deficient mice. Agonist-induced hypertension is not limited to rodents but is also confirmed in dogs. Heterogeneous regional blood flow responses focused attention on the kidney where it is shown, to our knowledge for the first time, that the GPR81 gene is active in the microcirculation, from morphological assessment indicating the glomerular afferent arterioles, and that agonism robustly increases vascular resistance and reduces perfusion.

The hypertension is robust, persistent, and is observed in all 3 species examined. Increased TPR rather than increased CO is likely the major driver of this effect. The increase in vascular resistance was heterogeneous among the tissues, with robust increases seen in the kidney but not the cardiac tissue or hindlimbs. Regional flow measurements captured an equivalent of only approximately $20 \%$ of total CO, and therefore vasoconstrictor effects in other unmeasured tissues/organs cannot be excluded. Interestingly, while agonism increases blood pressure, the chronic global deficiency of the receptor in the knockout animals has no major influence on the 24-hour MAP profile, perhaps consistent with a low level of tonic target engagement on GPR81 due to relatively low levels of the endogenous ligand, lactate, under conditions of ordinary diurnal activity (see below).

Evidence is provided that the ET system is a major effector mechanism for the GPR81-agonist-induced vasoconstriction. We speculate that intense GPR81 agonism (induced physiologically by high lactate levels or pharmacologically) relays an acute stress signal in specific tissues of the body, triggering the local release of ET-1. This peptide is capable of inducing vasoconstriction in the majority of tissues of the body (25), but its predominantly paracrine/autocrine function (26) would tend to limit vasoconstriction to these specific tissues. The current work identifies the kidney as one of these, where ET-1 is known to be a highly potent vasoconstrictor (27). Indeed, in response to experimental renal ischemia, local interstitial lactate (as reported in ref. 28) can reach the levels needed for significant GPR81 activation (see below) and furthermore an 
A

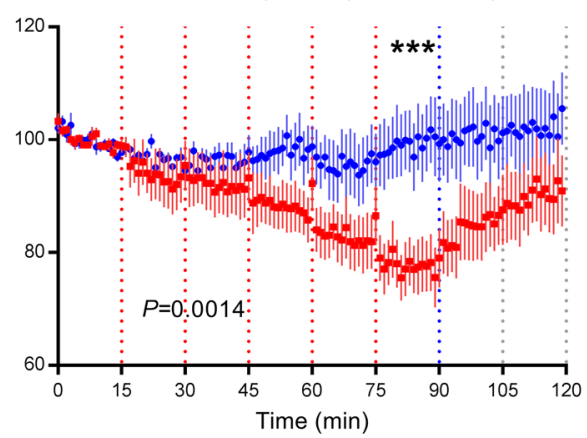

C

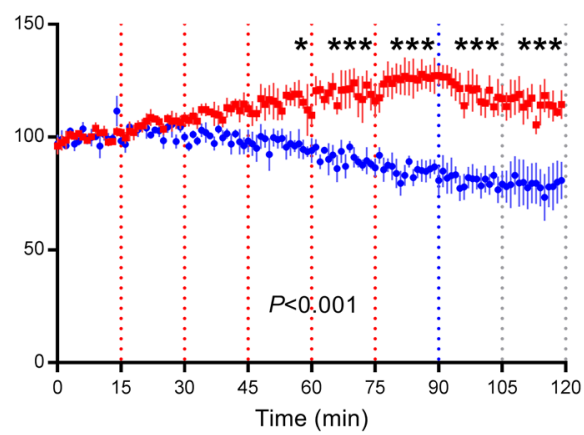

B

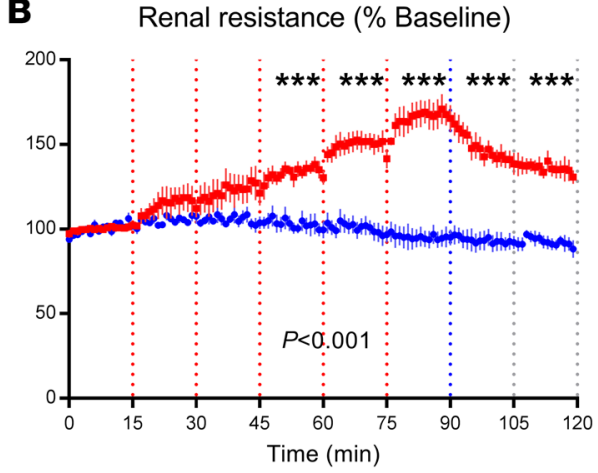

D

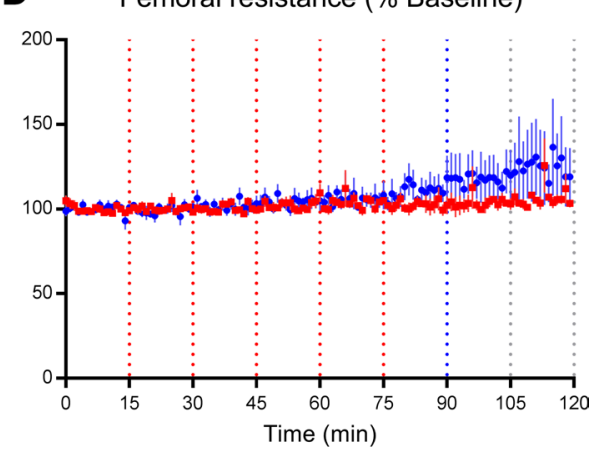

Figure 9. The GPR81 agonist, AZ2, exposure-dependently decreases renal perfusion, while increasing femoral perfusion, in anesthetized, ventilated dogs. Immediately after a 15-minute baseline control period ( $0-15$ minutes), AZ2 was administered i.v. in 5 consecutive escalating doses $(5.5$ to $550 \mathrm{nmol} / \mathrm{kg} / \mathrm{min}$, see Figure $3 \mathrm{~A}$ for diagram), commencing at 15 minutes and ending at 90 minutes, with the start of each dose change indicated by the broken red vertical lines. This was followed by a 30-minute washout period starting at the broken blue vertical line. Responses in AZ2treated (red) or vehicle-treated (blue) dogs, with data expressed as a percentage of their mean values during the baseline period. (A) Renal artery blood flow. (B) Renal vascular resistance. (C) Femoral artery blood flow. (D) Femoral artery vascular resistance. Results are the mean \pm SEM. $(\mathbf{A}-\mathbf{C}) P$ is treatment $x$ time interaction significance (repeatedmeasures ANOVA). ${ }^{*} P<0.05,{ }^{* *} P<0.001$ $A Z 2$ versus vehicle at the corresponding time period (Bonferroni corrected, $n=4$ ).

ET-mediated vasoconstriction is observed during the reperfusion phase $(29,30)$. Although the current work has focused on the kidney, owing to the very robust effects that were observed there, our analysis suggests that the vasoconstrictor effects mediated via the ET system are probably not limited to the kidney. Interestingly, a similar response to ischemia/reperfusion as observed in the kidney, and also involving ET, is seen in the intestine (31) but we have not yet looked at GPR81-agonist effects in this tissue. Beyond effects on resistance vessels, GPR81-mediated ET-1 release in capacitance vessels might also be responsible for the observed increase in CVP, compatible with the ability of ET-1 to induce constriction in large vessels (32).

Bosentan is a competitive antagonist of ET-1 (24) and therefore the incomplete suppression of the renal vasoconstrictor response to AZ2 may have been due to an insufficient dose of bosentan for this particular tissue, resulting in the observed slightly delayed and reduced maximal vascular resistance increase. Indeed, the potency of ET-1 to induce vasoconstriction in the renal vascular bed is approximately 10-fold higher than other tissues (27). Since the renal effect is only a fraction of the whole-body resistance effect, this could explain why the bosentan dose was able to virtually block the pressor effect but only partially block the renal effect.

The molecular mechanism linking the GPR81 and ET systems has not yet been elucidated. However, the major source of ET-1 is thought to be from the endothelial cells and our working hypothesis (depicted in Supplemental Figure 5) is that activation of GPR81 on the endothelial cells triggers a local release of vesicular ET-1. Unfortunately, the ISH imaging we have performed has insufficient resolution to identify the specific cellular address of GPR81 on the renal microvasculature. Activation of putative endothelial cell GPR81 could stimulate ET-1 secretion via a Gi-dependent lowering of cAMP. Thus, an inhibitory effect of cAMP on ET-1 secretion is provided by a number of in vitro studies of endothelial cells (33-36). GPR81-agonist-induced vasoconstriction in the renal circulation is rapid. If this is indeed mediated by ET-1, it implies rapid release of the preformed peptide, since de novo synthesis via translational regulation would presumably be far too slow. Fast release of ET-1 is certainly physiologically possible, as exemplified by the response to a cold pressor test (37). There are at least 2 identified types of ET-1-containing secretory vesicles in endothelial cells (38): rod-shaped Weibel-Palade bodies (WPB), whose major cargo is von Willebrand factor (VWF), and distinct punctate storage vesicles. A role for WPB exocytosis seems unlikely given that this process is stimulated by an increase, rather than a decrease, in cAMP levels (39). Thus, it seems more plausible that the source of ET-1 could be via exocytosis of the non-WPB storage granules which, apparently, can be very fast (40). 
A

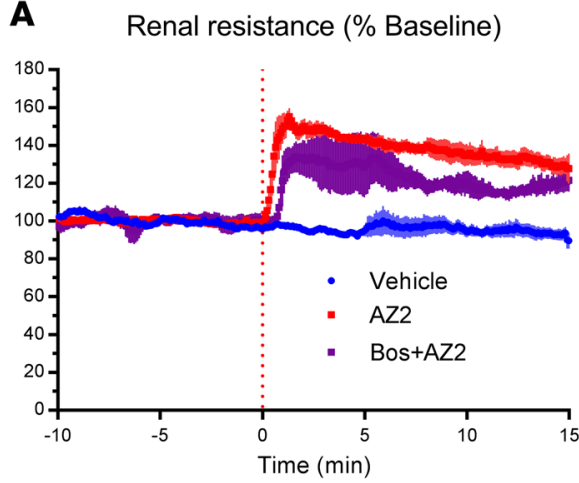

C

Renal blood flow (\% Baseline)

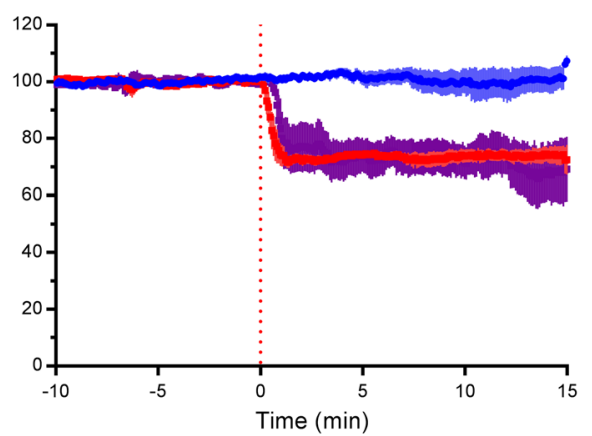

B

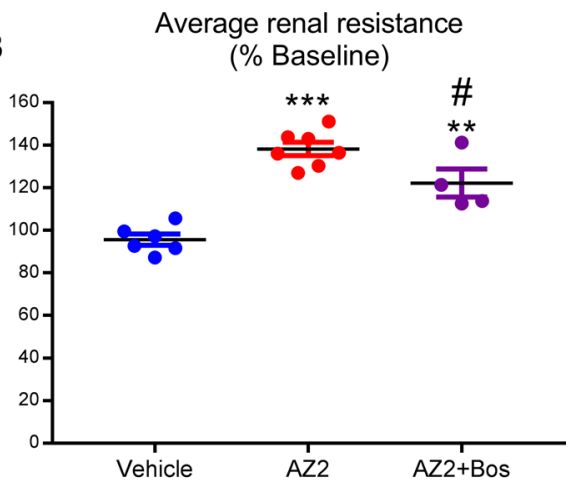

D

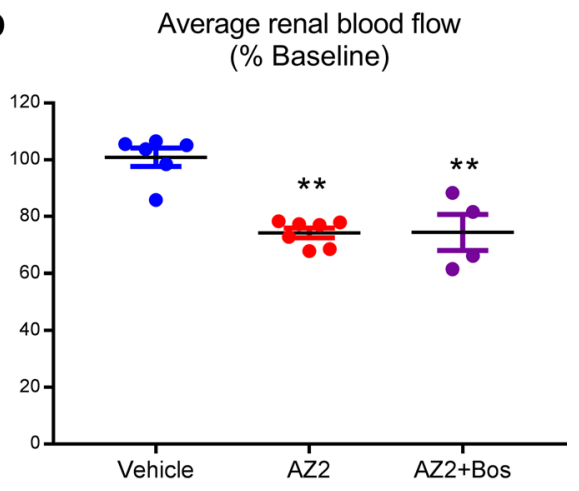

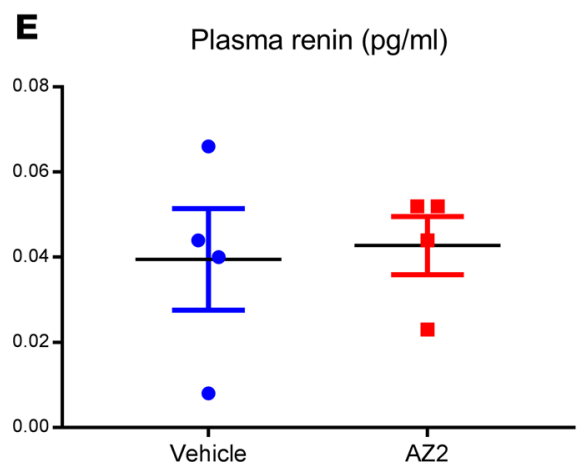

Figure 10. The GPR81 agonist, AZ2, rapidly increases renal vascular resistance, by an effect that is at least partially dependent on endothelin (ET) receptor agonism and does not affect plasma renin levels. Adult male Wistar rats were anesthetized and implanted with jugular and carotid catheters. Laparotomy was performed and a flow probe attached to the left renal artery, abdomen closed, and animals were left to stabilize for 1 hour. Following a 10-minute baseline period ( $t=-10$ to 0 minutes), either vehicle (blue symbols) or AZ2 $(1 \mu \mathrm{M} /$ $\mathrm{kg} / \mathrm{min}$ ) was given i.v. from 0-15 minutes. $A Z 2$ was given alone ( $A Z 2$, red symbols) or on top of pretreatment (given before -10 minutes), with the dual ET-A/B receptor antagonist, bosentan, $15 \mathrm{mg} / \mathrm{kg}$ i.v. (Bos+AZ2, purple symbols). Changes in renal vascular resistance and renal artery blood flow are expressed as percentages of their respective averages during the baseline period. (A) Minute-by-minute change in renal vascular resistance. (B) Mean change in renal resistance averaged over 0-15 minutes. (C) Minuteby-minute change in renal artery blood flow. (D) Mean change in renal artery blood flow averaged over 0-15 minutes. (E) Plasma renin levels after 15 minutes of vehicle or AZ2 $(n=4)$. Results are the mean \pm SEM (vehicle, $n=6$; AZ2, $n=7$; Bos+AZ2, $n=4) .{ }^{*} P$ $<0.05,{ }^{* *} P<0.01$ versus vehicle; ${ }^{\#} P<$ $0.05,{ }^{\#} P<0.01$ versus AZ2. ANOVA, followed up by multiple comparison test with Holm-Sidak correction.

The cardiovascular response to GPR81 agonism bears some of the hallmarks of the response to sympathetic activation: pressor effect and increased TPR due to a regionally selective vasoconstrictor response. Indeed, we have evidence for a role of adrenergic activation from the finding that the pressor effect of AZ2 could be substantially abolished using $\alpha$-AR blockade. But how do we reconcile this result with the fact that ET receptor blockade could also substantially abolish the pressor effect? A trivial explanation might be that the phentolamine results are nothing more than an experimental artifact. In this case, the conditions imposed by phentolamine, including severe hypotension, may have masked the true effector mechanism responsible for the hypertension. An alternative possibility is that the ET and adrenergic systems are serially coupled downstream of GPR81 activation (Supplemental Figure 5). In support of this, there is evidence that ET receptor A agonism can enhance adrenergic tone by at least 2 mechanisms: (a) via decreasing the reuptake of norepinephrine by the presynaptic nerve terminals at neuromuscular junctions (41) and (b) by increasing sympathetic tone (42).

Could the GPR81-mediated renovascular constriction and blood pressure-raising effects have physiological significance? Lactate infusions can certainly elevate blood pressure (e.g., in rats; see ref. 43) but in order for lactate sensing by GPR81 to be physiologically relevant it is necessary that endogenous lactate levels achieve sufficient concentrations to activate GPR81. We estimate (based on relative in vitro potencies for antilipolysis 


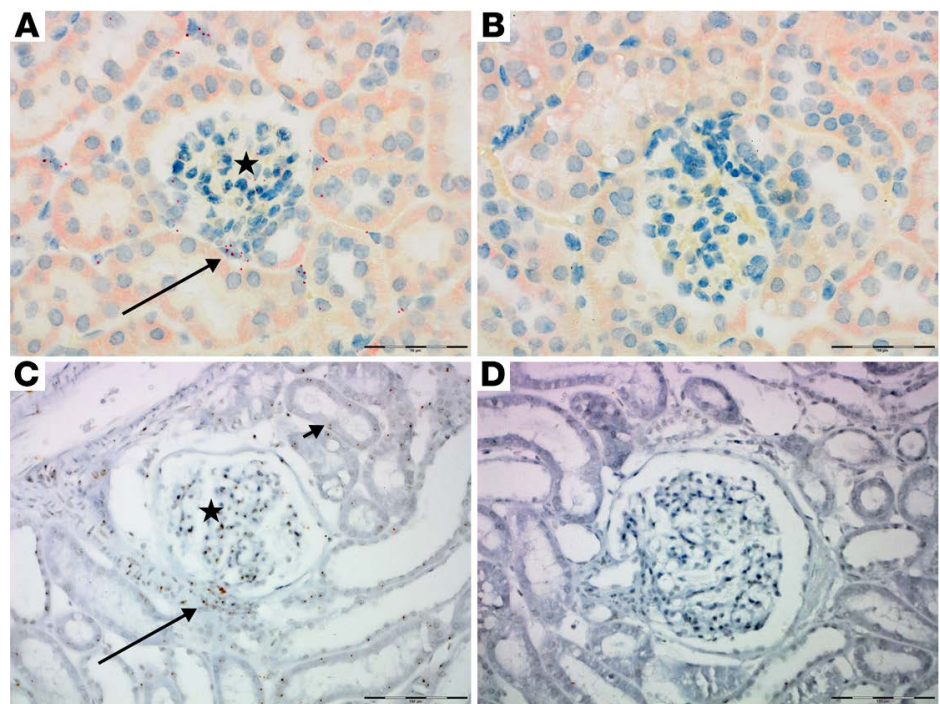

Figure 11. GPR81 expression is associated with the microvasculature of the kidney. In situ hybridization (ISH) image of wild-type mouse (A) and dog (C) kidney cortex displaying GPR81 mRNA expression at the vascular pole of the glomerula, including the juxtaglomerular afferent arteriole (arrows) close to the macula densa, and the basal glomerular tuft (stars). In the dog kidney (C) there is additional but less intense ISH stain for GPR81 mRNA over the tubular epithelial cells (short arrow). No GPR81 mRNA expression is seen in the kidney from GPR81-knockout mouse (B) and no staining in dog negative control mRNA ISH-stained slides (D). For the ISH detection a red dye was used for the mouse samples (A and $\mathbf{B})$ and a brown dye for the dog samples (C and $\mathbf{D})$. Scale bars: $50 \mu \mathrm{m}$ (A and $\mathbf{B})$ and $100 \mu \mathrm{m}$ (C and $\mathbf{D})$.

of lactate $[3,000 \mu \mathrm{M}]$ versus AZ2 $[0.58 \mu \mathrm{M}]$ in adipocytes, as well as plasma protein binding for AZ2 [81\%]) that lactate levels of approximately $4 \mathrm{mM}$ would have GPR81 target engagement equivalent to the plasma AZ2 levels needed to induce marked renal vasoconstriction and hypertension. This lactate concentration is certainly above normal systemic resting levels, but during intense exercise or locally in the kidney under ischemic conditions, such levels may be reached $(4,28)$. Therefore, it does indeed seem that endogenous lactate can achieve the levels needed to induce physiological GPR81-mediated cardiovascular effects.

We hypothesize that GPR81-induced vasoconstriction is a physiological defense response to high systemic lactate levels for preserving systemic homeostasis in situations of extreme stress, e.g., intense exercise, hypoxia, or injury. Blood flow would be diverted away from the kidney (and other as yet undefined tissues) to bolster perfusion in critical tissues, including heart and skeletal muscle. This would augment classic systemic stress-induced sympathetic outflow responses leading to renal vasoconstriction (44) while minimizing conflict with ordinary metabolic control. Even the established antilipolytic effect of GPR81 agonism may represent an appropriate response in this situation, by limiting FFA availability and thereby optimizing the use of oxygen for ATP production (45). Such a novel whole-body homeostatic mechanism is perhaps not that surprising given recent evidence that lactate sensing by another GPCR, Olfr78, plays a critical role in the carotid body by sensing hypoxia and breathing regulation (46). Locally in the kidney, vasoconstriction in response to physiological or pathophysiological GPR81 agonism seems incompatible with blood flow autoregulation and tissue survival. Thus, an accumulation of lactate might worsen ischemic damage, especially if glomerular filtration rate, the major determinant of kidney metabolic rate and oxygen demand (47), remains unchanged. In line with this, chronic hypoxia in the tubulointerstitium of the kidney is thought to be a driver of impaired glomerular function and fibrosis leading to the development of end-stage renal disease (48).

There are parallels between our findings with GPR81 agonism and the responses of GPR91 to its endogenous ligand succinate (49). Thus, succinate, which is increased in the situation of ischemia (50), has been reported to inhibit adipose tissue lipolysis via Gi-coupled signalling suppression of cAMP (51) and has a hypertensive effect that is dependent on GPR91 (52). In addition, the local tissue expression of GPR91 in the kidney also has some similarity to GPR81, particularly its expression in the afferent arteriole (53-55). In contrast to the situation for GPR81 though, the hypertensive effect of GPR91 agonism may be caused by Gs-mediated release of renin (54).

We show that pharmacologic GPR81 agonism improves insulin sensitivity in preclinical disease models of the metabolic syndrome. These results are consistent with our hypothesis that suppression of lipolysis, especially in the postprandial state, would enhance glucose control due to decreased FFA fuel competition with glucose and increased insulin sensitivity $(56,57)$. Therefore, achieving postprandial substance exposure was an important consideration in the design of the repeated-dosing studies. The GPR81 agonists evaluated in this study were potent and sufficiently selective (vs. GPR109a) to allow a dosing window that could effectively suppress FFA levels in vivo entirely via GPR81 (as shown by the data in the genetically deficient mice). 
A key finding is that the antilipolysis and metabolic improvements are seen in the absence of body weight gain. This is important for the general principle of antilipolysis in the intended target patient group with obesity-driven metabolic syndrome and perhaps unexpected given a previous publication showing that GPR81 deficiency is associated with reduced body weight gain when challenged with a high-fat diet (3). The current lack of body weight gain with GPR81 agonism is probably due to incomplete around-the-clock FFA suppression. This result is analogous to other principles that partially inhibit lipolysis, e.g., following partial deactivation of hormone-sensitive lipase (58) or intermittent GPR109a activation (57, 59). While the metabolic effects are impressive, these unfortunately occur at agonist exposures causing hypertension. This would make the development of full GPR81 agonists extremely challenging, especially given the excess risk of cardiovascular mortality and morbidity in the target patient population $(60,61)$.

In conclusion, the current results extend the role of the metabolite sensor, GPR81, beyond regulation of adipocyte lipolysis to cardiovascular function including control of renal vascular resistance. Future studies are needed to further explore the physiological/pathophysiological significance of these actions. In addition, the data provide further support for the concept of controlling lipolysis as a means of improving metabolic control in conditions of insulin resistance.

\section{Methods}

Synthesis of $A Z 1$ and $A Z 2$. The synthesis and in vitro characterization of AZ1 (2-chloro-4-ethoxy- $N$-[[6[(1-methyl-4-piperidyl)sulfonyl]-1,3-benzothiazol-2-yl]carbamoyl]-5-pyrazol-1-yl-benzamide) and AZ2 (2-chloro-4-ethoxy- $N$-[[6-[(4-methylpiperazin-1-yl)methyl]-1,3-benzothiazol-2-yl]carbamoyl]-5-morpholino-benzamide) as GPR81 agonists and their effects on inhibition of lipolysis in vitro are described in Supplemental Methods. The reference compound CHBA has been described previously (15).

In vivo pharmacokinetic $(P K)$ experiments. $\mathrm{PK}$ properties (clearance $[\mathrm{CL}]$, half-life $\left[\mathrm{t}_{1 / 2}\right]$, and bioavailability $[\mathrm{F} \%])$ of selected compounds, estimated in male Wistar rats and C57BL/6 mice, were based on repeated blood sampling 0-24 hours following i.v. or per os (p.o.) administration. Doses were $2 \mu \mathrm{mol} / \mathrm{kg}$ for i.v. and $8 \mu \mathrm{mol} / \mathrm{kg}$ for p.o. experiments.

FFA lowering in fasted mice. Lean female mice (11 weeks old C57BL/6JOlaHsd, Harlan Laboratories), as well as, WT and GPR81-KO mice (14 \pm 1 weeks old, on C57BL/6JOlaHsd background) were randomized to treatment groups based on body weight the day before the study. A terminal blood sample was collected in the 6-hour fasting state. Two hours before this, the mice were orally administered with either vehicle $(0.5 \%$ hydroxypropyl methylcellulose [HPMC], pH 4.2) or AZ1 at 5 or $20 \mu \mathrm{mol} / \mathrm{kg}$ or AZ2 at 50 $\mu \mathrm{mol} / \mathrm{kg}$. Blood was collected under isoflurane anesthesia into EDTA tubes kept on ice until centrifugation at $4^{\circ} \mathrm{C}$. Plasma was stored at $-20^{\circ} \mathrm{C}$ until analysis of FFA.

Generation of GPR81-null mice. A conditional KO strategy, flanking Gpr81 exon 1 with LoxP sites, was used to target the Gpr81 locus to generate mice carrying conditional $\mathrm{KO}$ alleles at this site. The targeting vector was built using homologous recombination in bacteria (62). A C57 mouse BAC served as template for the extraction of homology arms of the targeting vector. The targeting vector (Supplemental Figure 6) contained an frt-flanked neomycin phosphotransferase, Neo-selectable marker cassette. After linearization, the targeting construct was electroporated into AZX1, a C57BL/6JOlaHsd-derived embryonic stem cell line. PCR screens and Southern blot analyses (not shown) revealed clones that had undergone the desired homologous recombination event. Several of these clones were expanded and injected into BALB/cOlaHsd blastocysts to generate chimeric males that were then bred to C57BL/6JOlaHsd females, and black-coated offspring were genotyped on both sides of the homology arms for correct integration into the Gpr81 locus. The Neo-selectable marker cassette, which was flanked by frt sites, was deleted after subsequent breeding to mice expressing flp recombinase under the CAG promoter. Gpr81 exon 1, which was flanked by loxP sites, was deleted after subsequent breeding to mice expressing Cre recombinase under the R26 promoter. Gpr81 deficiency was confirmed by RT-PCR analyses, designed to amplify fragments within the deleted DNA sequence, using liver-derived RNA from WT, heterozygous, and homozygous Gpr81-KO mice. Total RNA was extracted with TRIZol Reagent (Invitrogen) according to the manufacturer's protocol. Reverse transcription was performed with SuperScript First-Strand (Invitrogen) followed by PCR to confirm the targeting strategy: forward, 5'-CATCTTGTTCTGCTCGGTCA-3' and reverse, 5'-TGGTGTAGAATTTGGGGAGC-3'. No expression of Gpr81 was observed in the homozygous Gpr81-KO mice. The Gpr81-KO mice were healthy and appeared normal, displaying no obvious adverse phenotype during the SHIRPA observations at 4 to 8 weeks of age. 
GPR81 expression in adipose tissue from ob/ob and lean controls. Gonadal white adipose tissue was collected from euthanized 10-week-old lean and obese mice (B6.V-Lep ${ }^{\mathrm{ob}} / \mathrm{OlaHsd}$, Harlan Laboratories) and directly frozen in liquid nitrogen, then stored at $-80^{\circ} \mathrm{C}$ until analysis. RNA was prepared using the Qiagen RNAeasy kit and cDNA synthesized using the High Capacity cDNA Reverse Transcription Kit (Invitrogen). Differences in gene expression (relative to 36B4) were determined by quantitative RT-PCR: reverse primer, TCGAAATTGGCATCTCTTCTGA; forward primer, CAGCCTGAAGCCCAAACG; and probe (5'FAM-3'TAMRA), CCAGGACGCACGAAGACGCG.

DIO mousestudy. Ten-week-old male mice (C57/BL6N, Janvier Labs) were placed on a high-fat diet (D12492, $60 \%$ fat, Research Diets). After 15 weeks the mice were put on a reverse-phase 12-hour light/dark cycle (lights off 9:30 am) and 2 weeks later were sham gavaged, once daily, for 1 week. Then mice were gavaged ( $5 \mathrm{ml} /$ $\mathrm{kg}$ ) with either vehicle $(0.5 \% \mathrm{HPMC})$ or AZ1 $20 \mu \mathrm{mol} / \mathrm{kg} /$ day q.d. at $8 \mathrm{am}$, for 28 days. Following 3 weeks of treatment, an oral glucose tolerance test $(1 \mathrm{~g} / \mathrm{kg})$ was performed in the 4-hour fasted state. Blood samples were collected from the tail vein for plasma glucose (glucose reagent TR15498, Thermoelectron Infinity) and insulin (Insulin, mouse, Ultrasensitive ELISA, Alpco Immunoassays) analysis at 0, 15, 30, 60, and 120 minutes after the glucose load. On the final study day, mice were fasted for 4 hours before a terminal blood sample was collected in EDTA tubes (Mini collect K3EDTA, Sarstedt) following cervical dislocation in carbon dioxide-anesthetized mice for analysis of metabolic biomarkers and substance levels. Plasma was stored at $-20^{\circ} \mathrm{C}$ until analysis.

FFA suppression and cardiovascular responses in anesthetized rats. Male Wistar rats (Harlan), 250-350 g, were fasted overnight and then anesthetized with thiobutabarbital $135 \mathrm{mg} / \mathrm{kg}$, i.p. (Inactin, Research Biochemicals International). Tracheotomy (PE240) was performed and catheters (PE50) were inserted into the carotid artery for blood sampling, as well as MAP and HR measurements and the jugular vein for infusion of GPR81 agonist or vehicle. Saline/Na-citrate $(0.02 \mathrm{M})$ was infused $(6 \mu 1 / \mathrm{min})$ into the arterial catheter to locally prevent clotting. Body temperature was measured with a rectal probe and kept at $37.5^{\circ} \mathrm{C}$ via feedback control of a heating lamp. After preparation, the animals were left to stabilize for 2 hours. To obtain in vivo FFA-lowering potency the following protocol was used. After a 15-minute baseline period, 4 graded escalating infusion rates $(1 \times, 3 \times, 10 \times$, and $30 \times)$ of test substance (or an equivalent volume of vehicle) were applied sequentially for 30 minutes per step. Arterial blood samples were collected during the baseline period and the end of each dose period for measurement of plasma FFA and test-substance concentrations. Based on the concentration-response and dose-response data generated, FFA-lowering potencies in terms of estimated unbound test substance concentration $\left(\mathrm{EC}_{50}\right)$ and dose $\left(\mathrm{ED}_{50}\right)$ were estimated. To obtain information about effects on cardiovascular control a separate protocol was used. After a 15-minute baseline period, test substance or vehicle was infused i.v. at a single fixed infusion rate $\left(\sim 4 \times \mathrm{ED}_{50}\right)$ that was relevant but not excessive for FFA suppression. MAP and HR were monitored during baseline and the 15-minute test substance/vehicle infusion period during which blood samples were restricted to 2 occasions. After the blood pressure recording period, the test substance/vehicle infusion was stopped and blood samples were collected periodically for FFA analysis and test substance concentrations.

Involvement of ET and adrenergic systems in the AZ2-induced pressor and renal vascular resistance effects. Bosentan, a nonselective ET receptor antagonist, was given i.v. 20 minutes before AZ2 infusion start at a dose of $15 \mathrm{mg} / \mathrm{kg}$, based on the reported ability to markedly suppress the pressor effect of exogenously administered ET-1 (63). Phentolamine, the nonselective $\alpha$-AR antagonist, was administered i.v. in several short infusions over a 20 -minute period (total dose $10 \mathrm{mg} / \mathrm{kg}$ ), with the final partial dose given 10 minutes prior to AZ2 infusion start. $\alpha$-AR blockade was verified by confirming abolition of acute pressor response to phenylephrine (7 $\mu \mathrm{g} / \mathrm{kg}$ i.v.), an $\alpha$-AR agonist.

Mouse blood pressure measurements. HD-X11 (Data Sciences International) devices for telemetry recording of blood pressure were implanted in WT and GPR81-KO mice weighing more than $25 \mathrm{~g}$ (3-6 months of age). The catheter for blood pressure sensing was placed in the left carotid artery and the transmitter was placed on the right flank. During the first postoperative days, the mice received ketoprofen (Comforion Vet, Orion Pharma Animal Health) $3 \mathrm{mg} / \mathrm{kg}$, b.i.d. in jelly (Jelly Crystals, Jotis, raspberry flavor). Animals recovered, regaining their preoperative body weights for at least 2 weeks before the treatment study was initiated. Baseline recordings were made over 2 days followed by 4 days with oral administration of vehicle or AZ2 $(50 \mu \mathrm{mol} / \mathrm{kg} /$ day). Animals were dosed between 10:00 and 10:30 each day, during which the cages were temporarily out of receiver range with signal loss. Average MAP every hour during the 4 dosing days was compared with mean MAP recorded for baseline day 1 and 2 for the same time point. Data are presented as mean change from baseline over 24 hours. 
Systemic cardiovascular and regional blood flow responses in the anesthetized, ventilated dog Preparation. Male $(n=4)$ and female $(n=4)$ beagle dogs (Rååhöjden), $11.2-17.5 \mathrm{~kg}$, were cannulated with a percutaneous polyethylene catheter (Venflon $1.0 \mathrm{~mm}$, Becton Dickinson) into a cephalic vein for administration of anesthetics, sodium bicarbonate, and Ringer's solution. Anesthesia was induced with an i.v. infusion of propofol (Lipuro, B. Braun Melsungen AG), 6-8 mg/kg with top-up dosing of 2-3 mg/kg if needed. $\alpha$-Chloralose $[\alpha-\mathrm{D}(+)$-gluco-chloralose, Merck] was then given as an i.v. bolus injection $(100 \mathrm{mg} /$ $\mathrm{kg}$ ) followed by a continuous infusion $(25-50 \mathrm{mg} / \mathrm{kg} / \mathrm{h}$ ). The dogs were intubated and ventilated (Servo Ventilator 900C, Siemens Elema) with room air. The respiratory rate was held constant at $15 \mathrm{cycles} / \mathrm{min}$. During the preparation period the anesthesia was supplemented with a propofol infusion of $4-6 \mathrm{mg} / \mathrm{kg} / \mathrm{h}$. Blood gases and $\mathrm{pH}$ were adjusted to physiological levels by regulating the tidal volume and infusion of sodium bicarbonate $(600 \mathrm{mM})$. Ringer's solution was infused continuously, $10 \mathrm{ml} / \mathrm{kg} / \mathrm{h}$, to replace fluid loss. Body temperature was maintained between $35.0^{\circ} \mathrm{C}$ and $38.0^{\circ} \mathrm{C}$ throughout the experiment by external heating and use of blankets. A polyethylene catheter (Intramedic PE-90 Clay Adams, Becton Dickinson) was inserted via a branch into the right saphenous vein to be used for administration of AZ2 or vehicle.

Instrumentation for hemodynamic measurements. A polyethylene catheter (Intramedic PE-200 Clay Adams, Becton Dickinson, Sparks, MD, USA) was inserted into the right saphenous artery for blood sampling for analysis of blood gases, $\mathrm{pH}$, and plasma AZ2. The right external jugular vein was exposed and a catheter (Intramedic PE-200 Clay Adams) advanced to the right atrium for measurements of CVP (Transducer PVB). A thermistor (AstraZeneca R\&D) for body temperature measurement was positioned in the same jugular vein. A dual-sensor pressure transducer (Millar Micro-Tip SPC-771, Millar Instruments) was inserted via the right carotid artery, with the proximal transducer placed in the ascending aorta (for measurement of MAP) and the distal one in the left ventricle. The left femoral artery was exposed and femoral artery blood flow was measured with a $3.0-\mathrm{mm}$ ultrasonic transit-time volume flow sensor (T403 Transonic System Inc.). Thoracotomy was performed via the left fifth intracostal space and the pericardium was opened. $\mathrm{CO}$ and stroke volume were measured with a $14-\mathrm{mm}$ ultrasonic flow sensor (T403) placed on the ascending aorta. The left descending coronary artery blood flow was measured with a 1.5-mm ultrasonic flow sensor (T403) placed on the proximal part of the left descending coronary artery. Laparotomy was performed via a midline incision and a 2.5 -mm ultrasonic flow sensor (T403) was placed on the left renal artery for measurement of RAF. Urine was drained continuously by gravity using a caterer in the urinary bladder (Intramedic PE-200 Clay Adams). Vascular resistances were computed on line, continuously from the measurement of instantaneous regional blood flow and MAP. Absolute values are expressed in SI units.

Protocol. A stabilization period of approximately 3 hours elapsed between completion of the surgical preparation and commencement of the vehicle/AZ2 infusion. The AZ2 group was infused with vehicle ( $5 \%$ cyclodextrin plus $4 \%$ mannitol) via the cephalic vein and then 5 consecutive escalating doses of AZ2: $5.5,16.5,55,165$, and $550 \mathrm{nmol} / \mathrm{kg} / \mathrm{min}$, with each dose level including vehicle applied for 15 minutes. The volume infusion rate was held constant at $32 \mu 1 / \mathrm{kg} / \mathrm{min}$. The control group was infused with an equivalent volume of vehicle. At the end of the highest dose, interval substance/vehicle infusion was terminated and the final period of the experiment was a washout period of 30 minutes. Blood samples were collected in conjunction with the end of each dose period and during the washout period for both substance and control group. Dogs were euthanized at experiment termination using an overdose of approximately $3 \mathrm{~g}$ Na-pentabarbitone (Allfatal Vet, Omnidea AB).

Renalbloodflowinanesthetizedrats. Adult male Wistar rats were anesthetized and prepared with tracheal, jugular, and carotid catheters as described for the in vivo lipolysis studies (above). Laparotomy was then performed to expose the left renal artery and a $1.5-\mathrm{mm}$ flow sensor (Transonic System Inc.) was attached to the artery. A transmission gel (Aquasonic, Parker Laboratories Inc.) was applied around the probe and the abdomen was closed. Animals were left to recover for 60 minutes. Following a 10 -minute baseline pretreatment period, $\mathrm{AZ2}(1 \mu \mathrm{mol} / \mathrm{kg} / \mathrm{min})$ or vehicle ( $5 \%$ mannitol, $\mathrm{pH} \sim 4.6)$ was infused for 15 minutes at a rate of $50 \mu \mathrm{l} / \mathrm{kg} / \mathrm{min}$. MAP, HR, and renal blood flow were continuously recorded. Then, an arterial blood sample $(0.5 \mathrm{ml})$ was collected for the measurement of plasma renin (SEA889Ra, Cloud-Clone).

Cardiovascular measurements. A custom computer program, Pharmlab 6.0 (AstraZeneca R\&D), was used for recording of blood pressure and blood flow and calculating MAP, HR, and vascular resistances in all studies where these variables were monitored. 
In situ detection of Gpr81 mRNA in mouse and dog kidney. Tissue from dog kidney cortex, as well as GPR81-WT and -KO mice, was prepared for ISH, according to Wang et al. (64). Briefly, fresh tissue was cut into 3- to 4-mm pieces and fixed in 4\% neutral buffered formaldehyde solution for 32 hours at room temperature. Then, samples were dehydrated using a standard ethanol series followed by xylene and embedded in paraffin. Tissue sections were cut at $4-\mu \mathrm{m}$ thickness and mounted on Superfrost Plus slides (Thermo Fisher Scientific), then baked dry for 1 hour at $60^{\circ} \mathrm{C}$. The sections were then deparaffinized using xylene and ethanol and air dried. Customized probes were obtained from Advanced Cell Diagnostics for the detection of Gpr81 mRNA.

For the dog sections, the in situ mRNA amplification and labeling process was performed on the Discovery XT Automated IHC/ISH platform (Ventana Medical Systems Inc.) using the RNAscope VS Assay ISH method (Advanced Cell Diagnostics). The protocol includes several steps of signal amplification, followed by hybridization to HRP-labeled probes and detection using a chromogenic substrate DAB (brown stain).

For the mouse sections, the in situ mRNA amplification and labelling process was performed on the Bond RX, an Automated ISH platform (Leica Biosystems) using the RNAscope 2.5 LS Assay (Advanced Cell Diagnostics). The signal was amplified using multiple steps, followed by labeled probes and detected using the Bond Polymer Refine detection kit (red stain).

Stained slides were analyzed and photographed under a standard bright-field microscope.

Plasma analysis. Insulin levels were determined using a radioimmune assay (RI-13K, Millipore Corporation) performed on a 1470 Automatic Gamma Counter (PerkinElmer). Enzymatic colorimetric methods were used for analysis of glucose (Glucose HK CP, A11A01667, Horiba ABX), fructosamine (FR3133 Randox Laboratories Ltd), and FFAs (NEFA-HR(2), WaKO Chemicals GmbH). These enzymatic assays were performed on an ABX Pentra 400 (Horiba ABX). Substance levels were measured on a short reversedphase HPLC column with rapid gradient elution and MSMS detection using a triple quadrupole instrument with electrospray ionization and Selected Reaction Monitoring acquisition.

Statistics. Studies involving only 2 groups were analyzed using Student's $t$ tests. For comparisons between multiple categorical group data, 1-way ANOVA was followed up with post-hoc comparisons between pairs of groups made using Bonferroni or Holm-Sidak correction for multiple comparisons. Analysis of parameters measured over time was performed using 2-way repeated-measures ANOVA followed by testing of differences between individual time points using Bonferroni correction for multiple comparisons. In the dog study, continuously measured cardiovascular variables were represented by averages for each of the defined time periods: baseline, doses 1-5, and washout (divided into 2 intervals). For the dosing and washout periods the averaging was performed over the last 5 minutes of each interval when AZ2 plasma concentrations (during dosing) would be approaching steady state and corresponding to the timing of blood samples for plasma test substance concentrations. Profiles in the AZ2 and control animals were compared using the treatment $\times$ time interaction from the split-plot ANOVA as previously described (65). This interaction tests the null hypothesis that the time profiles are parallel in the treatment and control groups. Statistical analyses were performed using Prism (GraphPad Software Inc.). P less than 0.05 between the groups was considered to be a statistically significant difference.

Study approval. Experimental procedures were approved by the Local Ethics Review Committee on Animal Experiments (Gothenburg Region, Sweden). Use of adipose tissue from patients for lipolysis assays was approved by the Gothenburg Ethics board (Dnr: 482-07) and by written consent from the patients.

\section{Author contributions}

$\mathrm{KW}, \mathrm{PT}$, and NDO designed the research studies. JW generated the $G P R 81^{-1-}$ mice. $\mathrm{KW}$, PT, and JAB conducted the experiments. KW, NDO, PT, GB, PJ, and OF analyzed the data. KW, NDO, OF, PJ, JW, and GB wrote the manuscript.

\section{Acknowledgments}

We are grateful for our collaborators Birgitta Odén, Malin Lönn, and Staffan Edén at the Sahlgrenska University Hospital for providing the human fat biopsy material. We acknowledge Robert Unwin and Mathew Bailey (University of Edinburgh) for discussions on the observed renal effects; Anette Stringer, Anna Lindblom, and Dan Spets for their contributions to the telemetry study; Ann Kjellstedt for the ob/ob study; Göran Wahlund for in vivo screening in rats; Camilla Johansson for the in situ hybridization; Chris Lelliott for expression analysis; Kristina Nilsson for evaluating the high-throughput screening; and Arne 
Olsén and Frank Jansen for in vitro screening. We also acknowledge members of the following teams that have supported our studies: Laboratory Animal Supply, CVMD Medicinal Chemistry \& DMPK, Medicine Evaluation, Discovery Sciences and Drug Safety and Metabolism. The work in this study was fully funded by AstraZeneca R\&D.

Address correspondence to: Kristina Wallenius, CVMD iMed, Bioscience, AstraZeneca, SE-43183 Mölndal, Sweden. Phone: 46725399890; Email: Kristina.wallenius@astrazeneca.com.

1. Blad CC, Ahmed K, IJzerman AP, Offermanns S. Biological and pharmacological roles of HCA receptors. Adv Pharmacol. 2011;62:219-250.

2. Liu C, et al. Lactate inhibits lipolysis in fat cells through activation of an orphan G-protein-coupled receptor, GPR81. J Biol Chem. 2009;284(5):2811-2822.

3. Ahmed K, et al. An autocrine lactate loop mediates insulin-dependent inhibition of lipolysis through GPR81. Cell Metab. 2010;11(4):311-319.

4. van Loon LJ, Greenhaff PL, Constantin-Teodosiu D, Saris WH, Wagenmakers AJ. The effects of increasing exercise intensity on muscle fuel utilisation in humans. J Physiol (Lond). 2001;536(Pt 1):295-304.

5. Andersen LW, Mackenhauer J, Roberts JC, Berg KM, Cocchi MN, Donnino MW. Etiology and therapeutic approach to elevated lactate levels. Mayo Clin Proc. 2013;88(10):1127-1140.

6. Abi-Saab WM, et al. Striking differences in glucose and lactate levels between brain extracellular fluid and plasma in conscious human subjects: effects of hyperglycemia and hypoglycemia. J Cereb Blood Flow Metab. 2002;22(3):271-279.

7. Berkowitz BA, Bansal N, Wilson CA. Non-invasive measurement of steady-state vitreous lactate concentration. NMR Biomed. 1994;7(6):263-268.

8. Ellmerer M, et al. Lactate metabolism of subcutaneous adipose tissue studied by open flow microperfusion. J Clin Endocrinol Metab. 1998;83(12):4394-4401.

9. Langemann H, Alessandri B, Mendelowitsch A, Feuerstein T, Landolt H, Gratzl O. Extracellular levels of glucose and lactate measured by quantitative microdialysis in the human brain. Neurol Res. 2001;23(5):531-536.

10. MacLean DA, Bangsbo J, Saltin B. Muscle interstitial glucose and lactate levels during dynamic exercise in humans determined by microdialysis. J Appl Physiol. 1999;87(4):1483-1490.

11. Lafontan M, Langin D. Lipolysis and lipid mobilization in human adipose tissue. Prog Lipid Res. 2009;48(5):275-297.

12. Boden G, Shulman GI. Free fatty acids in obesity and type 2 diabetes: defining their role in the development of insulin resistance and beta-cell dysfunction. Eur J Clin Invest. 2002;32 Suppl 3:14-23.

13. DeFronzo RA. Insulin resistance, lipotoxicity, type 2 diabetes and atherosclerosis: the missing links. The Claude Bernard Lecture 2009. Diabetologia. 2010;53(7):1270-1287.

14. Unger RH. Lipotoxicity in the pathogenesis of obesity-dependent NIDDM. Genetic and clinical implications. Diabetes. 1995;44(8):863-870

15. Dvorak CA, et al. Identification of hydroxybenzoic acids as selective lactate receptor (GPR81) agonists with antilipolytic effects ACS Med Chem Lett. 2012;3(8):637-639.

16. Sakurai T, et al. Identification of a novel GPR81-selective agonist that suppresses lipolysis in mice without cutaneous flushing. Eur J Pharmacol. 2014;727:1-7.

17. Hein TW, Xu W, Kuo L. Dilation of retinal arterioles in response to lactate: role of nitric oxide, guanylyl cyclase, and ATPsensitive potassium channels. Invest Ophthalmol Vis Sci. 2006;47(2):693-699.

18. Kolko M, et al. Lactate transport and receptor actions in retina: potential roles in retinal function and disease. Neurochem Res. 2016;41(6):1229-1236.

19. Lauritzen KH, et al. Lactate receptor sites link neurotransmission, neurovascular coupling, and brain energy metabolism. Cereb Cortex. 2014;24(10):2784-2795.

20. Morland C, et al. The lactate receptor, G-protein-coupled receptor 81/hydroxycarboxylic acid receptor 1: Expression and action in brain. J Neurosci Res. 2015;93(7):1045-1055.

21. Roland CL, et al. Cell surface lactate receptor GPR81 is crucial for cancer cell survival. Cancer Res. 2014;74(18):5301-5310.

22. Feingold KR, Moser A, Shigenaga JK, Grunfeld C. Inflammation inhibits GPR81 expression in adipose tissue. Inflamm Res. 2011;60(10):991-995.

23. Wanders D, Graff EC, Judd RL. Effects of high fat diet on GPR109A and GPR81 gene expression. Biochem Biophys Res Commun. 2012;425(2):278-283.

24. Clozel M, et al. Pharmacological characterization of bosentan, a new potent orally active nonpeptide endothelin receptor antagonist. J Pharmacol Exp Ther. 1994;270(1):228-235.

25. Allcock GH, Warner TD, Vane JR. Roles of endothelin receptors in the regional and systemic vascular responses to ET-1 in the anaesthetized ganglion-blocked rat: use of selective antagonists. Br J Pharmacol. 1995;116(5):2482-2486.

26. Kohan DE, Inscho EW, Wesson D, Pollock DM. Physiology of endothelin and the kidney. Compr Physiol. 2011;1(2):883-919.

27. Pernow J, Franco-Cereceda A, Matran R, Lundberg JM. Effect of endothelin-1 on regional vascular resistances in the pig. J Cardiovasc Pharmacol. 1989;13 Supp1 5:S205-S206.

28. Amdisen C, Jespersen B, Møldrup U, Keller AK. The unsuitability of implantable Doppler probes for the early detection of renal vascular complications - a porcine model for prevention of renal transplant loss. PLOS ONE. 2017;12(5):e0178301.

29. López-Farré A, Gómez-Garre D, Bernabeu F, López-Novoa JM. A role for endothelin in the maintenance of post-ischaemic renal failure in the rat. J Physiol (Lond). 1991;444:513-522.

30. Müller V, et al. Sexual dimorphism in renal ischemia-reperfusion injury in rats: possible role of endothelin. Kidney Int. 
2002;62(4):1364-1371

31. Oktar BK, et al. Endothelin receptor blockers reduce I/R-induced intestinal mucosal injury: role of blood flow. Am J Physiol Gastrointest Liver Physiol. 2002;282(4):G647-G655.

32. Davenport AP, et al. Endothelin. Pharmacol Rev. 2016;68(2):357-418.

33. Kanse SM, et al. Production of endothelin by vascular smooth muscle cells. J Cardiovasc Pharmacol. 1991;17 Suppl 7:S113-S116.

34. Magnusson A, Halldorsson H, Thorgeirsson G, Kjeld M. Endothelin secretion is regulated by cyclic AMP and phosphatase 2A in endothelial cells. J Cell Physiol. 1994;161(3):429-434.

35. Malek AM, Greene AL, Izumo S. Regulation of endothelin 1 gene by fluid shear stress is transcriptionally mediated and independent of protein kinase C and cAMP. Proc Natl Acad Sci USA. 1993;90(13):5999-6003.

36. Saito T, et al. Coordinate regulation of endothelin and adrenomedullin secretion by oxidative stress in endothelial cells. Am J Physiol Heart Circ Physiol. 2001;281(3):H1364-H1371.

37. Fyhrquist F, Saijonmaa O, Metsärinne K, Tikkanen I, Rosenlöf K, Tikkanen T. Raised plasma endothelin-I concentration following cold pressor test. Biochem Biophys Res Commun. 1990;169(1):217-221.

38. Russell FD, Skepper JN, Davenport AP. Evidence using immunoelectron microscopy for regulated and constitutive pathways in the transport and release of endothelin. J Cardiovasc Pharmacol. 1998;31(3):424-430.

39. Goligorsky MS, Patschan D, Kuo MC. Weibel-Palade bodies--sentinels of acute stress. Nat Rev Nephrol. 2009;5(7):423-426

40. Goel A, Su B, Flavahan S, Lowenstein CJ, Berkowitz DE, Flavahan NA. Increased endothelial exocytosis and generation of endothelin-1 contributes to constriction of aged arteries. Circ Res. 2010;107(2):242-251.

41. Isaka M, Kudo A, Imamura M, Kawakami H, Yasuda K. Endothelin receptors, localized in sympathetic nerve terminals of the heart, modulate norepinephrine release and reperfusion arrhythmias. Basic Res Cardiol. 2007;102(2):154-162.

42. Lehmann LH, et al. Essential role of sympathetic endothelin A receptors for adverse cardiac remodeling. Proc Natl Acad Sci USA. 2014;111(37):13499-13504.

43. Wikander I, Roos T, Stakkestad A, Eriksson E. Sodium lactate elicits a rapid increase in blood pressure in Wistar rats and spontaneously hypertensive rats. Effect of pretreatment with the antipanic drugs clomipramine and alprazolam. Neuropsychopharmacology. 1995;12(3):245-250.

44. Millard RW, Higgins CB, Franklin D, Vatner SF. Regulation of the renal circulation during severe exercise in normal dogs and dogs with experimental heart failure. Circ Res. 1972;31(6):881-888.

45. Opie LH. Metabolism of free fatty acids, glucose and catecholamines in acute myocardial infarction. Relation to myocardial ischemia and infarct size. Am J Cardiol. 1975;36(7):938-953.

46. Chang AJ, Ortega FE, Riegler J, Madison DV, Krasnow MA. Oxygen regulation of breathing through an olfactory receptor activated by lactate. Nature. 2015;527(7577):240-244

47. Takiyama Y, Haneda M. Hypoxia in diabetic kidneys. Biomed Res Int. 2014;2014:837421.

48. Mimura I, Nangaku M. The suffocating kidney: tubulointerstitial hypoxia in end-stage renal disease. Nat Rev Nephrol. 2010;6(11):667-678

49. Deen PM, Robben JH. Succinate receptors in the kidney. J Am Soc Nephrol. 2011;22(8):1416-1422.

50. Chouchani ET, et al. Ischaemic accumulation of succinate controls reperfusion injury through mitochondrial ROS. Nature. 2014;515(7527):431-435.

51. McCreath KJ, et al. Targeted disruption of the SUCNR1 metabolic receptor leads to dichotomous effects on obesity. Diabetes. 2015;64(4):1154-1167.

52. He W, et al. Citric acid cycle intermediates as ligands for orphan G-protein-coupled receptors. Nature. 2004;429(6988):188-193.

53. Robben $\mathrm{JH}$, et al. Localization of the succinate receptor in the distal nephron and its signaling in polarized MDCK cells. Kidney Int. 2009;76(12):1258-1267.

54. Toma I, et al. Succinate receptor GPR91 provides a direct link between high glucose levels and renin release in murine and rabbit kidney. J Clin Invest. 2008;118(7):2526-2534

55. Vargas SL, Toma I, Kang JJ, Meer EJ, Peti-Peterdi J. Activation of the succinate receptor GPR91 in macula densa cells causes renin release. J Am Soc Nephrol. 2009;20(5):1002-1011.

56. Lomonaco R, et al. Metabolic impact of nonalcoholic steatohepatitis in obese patients with type 2 diabetes. Diabetes Care. 2016;39(4):632-638.

57. Kroon T, Baccega T, Olsén A, Gabrielsson J, Oakes ND. Nicotinic acid timed to feeding reverses tissue lipid accumulation and improves glucose control in obese Zucker rats[S]. J Lipid Res. 2017;58(1):31-41.

58. Girousse A, et al. Partial inhibition of adipose tissue lipolysis improves glucose metabolism and insulin sensitivity without alteration of fat mass. PLoS Biol. 2013;11(2):e1001485.

59. Kroon T, Kjellstedt A, Thalén P, Gabrielsson J, Oakes ND. Dosing profile profoundly influences nicotinic acid's ability to improve metabolic control in rats. J Lipid Res. 2015;56(9):1679-1690.

60. Emdin CA, Rahimi K, Neal B, Callender T, Perkovic V, Patel A. Blood pressure lowering in type 2 diabetes: a systematic review and meta-analysis. JAMA. 2015;313(6):603-615.

61. Long MT, Fox CS. The Framingham Heart Study--67 years of discovery in metabolic disease. Nat Rev Endocrinol. 2016;12(3):177-183.

62. Datsenko KA, Wanner BL. One-step inactivation of chromosomal genes in Escherichia coli K-12 using PCR products. Proc Natl Acad Sci USA. 2000;97(12):6640-6645.

63. Filep JG, Fournier A, Földes-Filep E. Effects of the ETA/ETB receptor antagonist, bosentan on endothelin-1-induced myocardial ischaemia and oedema in the rat. Br J Pharmacol. 1995;116(2):1745-1750.

64. Wang F, et al. RNAscope: a novel in situ RNA analysis platform for formalin-fixed, paraffin-embedded tissues. J Mol Diagn. 2012;14(1):22-29.

65. Ludbrook J. Repeated measurements and multiple comparisons in cardiovascular research. Cardiovasc Res. 1994;28(3):303-311. 